medRxiv preprint doi: https://doi.org/10.1101/2021.12.09.21267566; this version posted December 14, 2021. The copyright holder for this preprint (which was not certified by peer review) is the author/funder, who has granted medRxiv a license to display the preprint in It is made available under a CC-BY-NC-ND 4.0 International license .

\title{
Oral antiviral clevudine compared with placebo in Korean COVID-19 patients with moderate severity
}

Joon-Young Song ${ }^{1}$, Yeon-Sook Kim², Joong-Sik Eom ${ }^{3}$, Jin-Yong Kim${ }^{4}$, Jin-Soo Lee ${ }^{5}$, Jacob Lee $^{6}$, Won-Suk Choi ${ }^{7}$, Jung-Yeon $\mathrm{Heo}^{8}$, Jang-Wook Sohn ${ }^{9}, \mathrm{Ki}^{-D e o k}$ Lee $^{10}$, Donghui Cho ${ }^{11}$, llyoung $\mathrm{Cho}^{12}$, Woo-Joo Kim ${ }^{1}$

1. Division of Infectious Diseases, Department of Internal Medicine, Korea University College of Medicine, Seoul, Korea.

2. Division of Infectious Diseases, Department of Internal Medicine, Chungnam National University School of Medicine, Daejeon, Republic of Korea.

3. Division of Infectious Diseases, Department of Internal Medicine, Gil Medical Center, Gachon University School of Medicine, Incheon, Republic of Korea.

4. Division of Infectious Diseases, Department of Internal Medicine, Incheon Medical Center, Incheon, Republic of Korea.

5. Division of Infectious Diseases, Department of Internal Medicine, Inha University School of Medicine, Incheon, Republic of Korea.

6. Division of Infectious Disease, Department of Internal Medicine, Kangnam Sacred Heart Hospital, Hallym University College of Medicine, Seoul, Republic of Korea.

7. Division of Infectious Diseases, Department of Internal Medicine, Korea University College of Medicine, Ansan Hospital, Ansan, Republic of Korea.

8. Department of Infectious Diseases, Ajou University School of Medicine, Suwon, Korea.

9. Division of Infectious Diseases, Department of Internal Medicine, Korea University College of Medicine, Seoul, Republic of Korea.

10. Department of Infectious Diseases, Myongji Hospital, Hanyang university medical center, NOTE: This preprint reports new research that has not been certified by peer review and should not be used to guide clinical practice. 
medRxiv preprint doi: https://doi.org/10.1101/2021.12.09.21267566; this version posted December 14, 2021. The copyright holder for this preprint (which was not certified by peer review) is the author/funder, who has granted medRxiv a license to display the preprint in It is made available under a CC-BY-NC-ND 4.0 International license .

Goyang, Republic of Korea.

11. Department of Surgery, Seoul Medical Center, Seoul, Republic of Korea.

12. Bukwang Pharm. Co. Ltd., Seoul, Republic of Korea.

Corresponding Author: Woo-Joo Kim, wjkim@korea.ac.kr

\section{Abstract}

Background: Clevudine, an antiviral drug for chronic hepatitis B virus infection, is expected to inhibit the replication of severe acute respiratory syndrome coronavirus 2 (SARS-CoV-2) virus. Therefore, we conducted a prospective, single-blind, proof of concept clinical study to examine the antiviral efficacy and safety of clevudine compared to placebo in Korean corona virus disease 19 (COVID-19) patients with moderate severity.

Methods: Adults with confirmed SARS-CoV-2 infection and symptom onset within 7 days were randomized 2:1 to $120 \mathrm{mg}$ clevudine or placebo to receive one of treatments orally once-daily for 14 days. Antiviral efficacy outcomes were the proportion of patients with real-time reverse transcription polymerase chain reaction (RT-PCR) negative result for SARS-CoV-2 infection and cycle threshold $(\mathrm{Ct})$ value changes from baseline. Clinical efficacy outcomes included proportion of patients who showed improvement in lung involvement by imaging tests, proportion of patients with normal body temperature, proportion of patients with normal oxygen saturation, and the changes in C-reactive protein (CRP) from baseline. Safety outcomes included changes in clinical laboratory tests, vital signs measurement, and physical examination from baseline, and incidence of adverse events.

Results: The proportion of patients with real-time RT-PCR negative test and Ct value changes showed no significant difference between clevudine group and placebo group. The changes in $\mathrm{Ct}$ value from baseline were significantly greater in clevudine group compared to placebo 
medRxiv preprint doi: https://doi.org/10.1101/2021.12.09.21267566; this version posted December 14, 2021. The copyright holder for this preprint (which was not certified by peer review) is the author/funder, who has granted medRxiv a license to display the preprint in

group in patients with hypertension, and patients who underwent randomization during the first 5 and 7 days after the onset of symptoms. All clinical efficacy outcomes had no significant difference between clevudine group and placebo group. Clevudine was well tolerated and there was no significant difference in safety profile between two treatment groups.

Conclusions: This is the first clinical study to compare the antiviral efficacy and safety of clevudine to placebo in Korean COVID-19 patients with moderate severity. The study has demonstrated a possible favorable outcome for the reduction of SARS-CoV-2 replication, with acceptable safety profile, when COVID-19 patients were treated with clevudine. Further largescale clinical studies, preferably with various clinical endpoints and virus titer evaluation, are required to better understand the effectiveness of using clevudine in COVID-19 treatment. Considering recent trend in clinical development for antiviral drugs, we need to design a clinical study aiming for reducing clinical risk of COVID-19 in mild to moderate patients with at least one risk factor for serious illness.

\section{Introduction}

A new species of coronavirus, severe acute respiratory syndrome coronavirus 2 (SARSCoV-2), first identified at Wuhan city of China in December 2019, causes the respiratory infection designated as corona virus disease 19 (COVID-19) has led to a global pandemic as announced by the World Health Organization (WHO) on 11 March $2020 .{ }^{1}$ Clinical symptoms of COVID-19 range from asymptomatic case to respiratory illness (pneumonia) with fever, sneeze, cough, and shortness of breath. ${ }^{2}$ Several demographic factors and comorbidities (e.g., hypertension, diabetes mellitus, and liver disease) are known to be associated with worse outcomes in COVID-19. ${ }^{3-5}$ In particular, hypertension is demonstrated as one of the high-risk factors associated with aggravation of severity and higher mortality in patients with COVID$19 .^{6,7}$ It is well known that SARS-CoV-2 viral load peaks at the time of symptom onset, and 
medRxiv preprint doi: https://doi.org/10.1101/2021.12.09.21267566; this version posted December 14, 2021. The copyright holder for this preprint (which was not certified by peer review) is the author/funder, who has granted medRxiv a license to display the preprint in It is made available under a CC-BY-NC-ND 4.0 International license

gradually decreases soon after. ${ }^{8}$ Based on this knowledge, various clinical trials and research studies of COVID-19 treatments have been designed to elucidate the effect of treatment initiation timing from symptom onset in COVID-19 management. ${ }^{9-11}$

SARS-CoV-2 is a single-stranded positive-sense RNA virus whose cell entry is mediated by the binding of the virus spike protein to angiotensin-converting enzyme 2 (ACE2), an enzyme attached to the membrane of cells. Subsequent viral-host membrane fusion allows the release of the viral RNA into the host cells. The $3 \mathrm{CL}$ protease (3CLpro), known as the main protease of the SARS-CoV-2, plays a major role to produce non-structural proteins (nsps) involving viral replication and transcription. Most prominently, nsp12 contains RNA-dependent RNA polymerase (RdRP) which catalyzes the template-directed viral RNA synthesis. ${ }^{12}$ Thus, $\mathrm{RdRP}^{13-17}, 3 C L$ pro $^{18-20}$, and host-viral fusion ${ }^{21,22}$ are promising targets for antiviral agents against SARS-CoV-2. In line with the knowledge that the severity of COVID-19 is strongly associated with viral replication leve ${ }^{23,24}$, it has been hypothesized that the direct-acting antiviral agents will be an effective approach in alleviating aggravation of COVID-19 symptoms and preventing the further spread of COVID-19.

Clevudine is an antiviral drug to treat chronic hepatitis B virus (HBV) infection. Unlike SARS-CoV-2, HBV has a relaxed-circular partially double DNA (rcDNA) genome. A covalently closed circular DNA (cccDNA)--the viral intermediate formed by DNA repair process in rcDNA-is transcribed into pregenomic RNA (pgRNA) by host DNA-dependent RNA polymerase. Thereafter, reverse transcription of pgRNA by RNA-dependent DNA polymerase generates rcDNA for viral shedding. ${ }^{25}$ Although clevudine is a pyrimidine analogue, it has antiviral effects on HBV by inhibiting the DNA polymerization of protein priming rather than incorporating the viral DNA. ${ }^{26,27}$ Based on this action mode of clevudine, it is expected that clevudine would have antiviral effects on SARS-CoV-2. Furthermore, recent molecular docking studies revealed that clevudine has strong inhibitory capabilities against 3CLpro and ACE2 of SARS- 
medRxiv preprint doi: https://doi.org/10.1101/2021.12.09.21267566; this version posted December 14, 2021. The copyright holder for this preprint (which was not certified by peer review) is the author/funder, who has granted medRxiv a license to display the preprint in It is made available under a CC-BY-NC-ND 4.0 International license .

CoV-2. ${ }^{28,29}$ Altogether, clevudine is hypothesized to inhibit the replication of SARS-CoV-2 virus. Therefore, we conducted a prospective, single-blind, proof of concept clinical study to examine the antiviral efficacy and safety of clevudine compared to placebo in Korean COVID-19 patients with moderate severity (BK-CLV-201, ClinicalTrials.gov identifier NCT04347915).

\section{Methods}

Clinical study oversight

Adults aged 19 years or older were eligible if they showed real-time reverse transcription polymerase chain reaction (RT-PCR) positive result for SARS-CoV-2 infection within 96 hours and had symptoms of COVID-19 within 7 days from screening to treatment initiation. Participants were randomized $2: 1$ to $120 \mathrm{mg}$ clevudine or matching placebo to receive one of treatments orally once-daily for 14 days (Figure 1). Planned number of patients was 60 and this sample size was chosen arbitrarily. Antiviral efficacy and safety were evaluated for 29 days after treatment initiation. For assessment of antiviral efficacy, nasopharyngeal swabs were collected at Day 1 (baseline), 4, 8, 11, 15, 22 and 29 for real-time RT-PCR test. Clinical laboratory tests were evaluated at Day 1, 4, 8, 15, 22 and 29, and adverse events (AEs) were monitored throughout the study.

\section{Antiviral efficacy outcome}

The primary antiviral efficacy outcome was the proportion of patients with real-time RTPCR negative result for SARS-CoV-2 infection at Day 15. Secondary antiviral efficacy outcomes were the proportion of patients with real-time RT-PCR negative result at Day 4, 8, 11, 22 and 29; as well as the changes in cycle threshold (Ct) value of $\mathrm{E}, \mathrm{RdRP}$, and $\mathrm{N}$ genes from baseline to Day 4, 8, 11, 15, 22 and 29. Real-time RT-PCR test for SARS-CoV-2 infection 
medRxiv preprint doi: https://doi.org/10.1101/2021.12.09.21267566; this version posted December 14, 2021. The copyright holder for this preprint (which was not certified by peer review) is the author/funder, who has granted medRxiv a license to display the preprint in It is made available under a CC-BY-NC-ND 4.0 International license .

was performed using Allplex ${ }^{\mathrm{TM}}$ 2019-nCoV Assay kit and sample was considered negative if all Ct values of target genes ( $\mathrm{E}, \mathrm{RdRP}$, and $\mathrm{N}$ genes) were 40 or higher.

Clinical efficacy outcome

Clinical efficacy outcomes included proportion of patients who showed improvement in lung involvement by imaging tests (e.g. X-Ray, CT-Scan) from baseline to Day 29, proportion of patients with normal body temperature, proportion of patients with normal oxygen saturation $\left(\mathrm{SpO}_{2}, \geq 95 \%\right)$ at Day 4, 8, 11, 15, 22 and 29, and the changes in C-reactive protein (CRP) from baseline to Day 4, 8, 15, 22 and 29.

Safety outcome

Safety outcomes included changes in clinical laboratory tests, vital signs measurement, and physical examination from baseline, and incidence of AEs and serious AEs (SAEs).

\section{Statistical analysis}

Efficacy analyses were conducted in intent-to-treat (ITT) population. The number and percentage of patients with real-time RT-PCR negative result for SARS-CoV-2 infection, patients with normal body temperature, patients with normal oxygen saturation at Day 4, 8, 11, 15, 22 and 29, and patients who showed improvement in lung involvement at Day 29 were summarized and between-treatment comparisons were conducted using Pearson's chisquare test or Fisher's Exact test. Changes in Ct value of E, RdRP, N genes, and CRP from baseline were presented as descriptive statistics (i.e. mean, standard deviations, median, min, max) and comparisons between treatments at each visit were conducted using a Two-sample 
medRxiv preprint doi: https://doi.org/10.1101/2021.12.09.21267566; this version posted December 14, 2021. The copyright holder for this preprint (which was not certified by peer review) is the author/funder, who has granted medRxiv a license to display the preprint in It is made available under a CC-BY-NC-ND 4.0 International license .

t-test or Wilcoxon's rank sum test. Analyses were performed using SAS Version 9.4 (SAS Institute Inc., Cary NC) and two-sided tests were performed using an alpha of 0.1 for betweentreatment comparisons. Safety analyses were based on the safety population which consisted of all patients who received at least 1 dose of study drug. The number of patients with AEs and adverse drug reactions (ADRs) in each treatment group were summarized using frequency distribution. Test values and change from baseline were summarized descriptively by treatment group for clinical laboratory test results, vital signs, and physical examination.

\section{Results}

\section{Patient Characteristics}

A total of 61 patients were analyzed as ITT population and safety population of which 41 and 20 patients were randomized in clevudine and placebo group, respectively. The mean age at baseline was $60.02( \pm 13.44)$ and $59.50( \pm 11.69)$ years in clevudine and placebo group, respectively. The most common clinical symptom of COVID-19 among all patients were fever (90.16\%), cough $(65.57 \%)$, and myalgia $(44.26 \%)$. A total of 28 patients $(45.90 \%)$ had hypertension at baseline, of which 19 and 9 patients were randomized in clevudine and placebo group, respectively. Of all patients, 34 and 49 patients were randomized within 5 and 7 days from the symptom onset, respectively. Baseline characteristics of the patients are shown in Table 1.

\section{Proportion of patients with real-time RT-PCR negative test result}

We evaluated the proportion of patients with real-time RT-PCR negative test result at Day $4,8,11,15,22$, and 29. 2 patients of ITT population were excluded from the analysis because they had negative result at baseline. There was no significant difference in the proportion of 
medRxiv preprint doi: https://doi.org/10.1101/2021.12.09.21267566; this version posted December 14, 2021. The copyright holder for this preprint (which was not certified by peer review) is the author/funder, who has granted medRxiv a license to display the preprint in It is made available under a CC-BY-NC-ND 4.0 International license .

patients with negative result between clevudine group and placebo group at every visit (Table 2).

Changes in Ct value of $E, R d R P, N$ genes from baseline

Changes in Ct values of E, RdRP, and $\mathrm{N}$ genes from baseline to Day 4, 8, 11, 15, 22, and 29 were evaluated. Ct values provided by real-time RT-PCR are highly associated with the copy number of viral RNA and viral load, implicating that higher Ct values relate to lower viral loads. ${ }^{30,31} \mathrm{Ct}$ values of all genes at baseline were significantly lower in clevudine group compared to placebo group. Considering that lower Ct values are related to a higher amount of target viral sequence, there was an imbalance in viral load between treatment groups. Clevudine group showed greater change in Ct values of all genes from baseline to all visits (except Day 8) than placebo group, but there was no significant difference between clevudine group and placebo group at every visit (Table 3 and Figure 2).

We conducted subgroup analysis by hypertension and time from the symptom onset to randomization on change in $\mathrm{Ct}$ values of $\mathrm{E}, \mathrm{RdRP}$, and $\mathrm{N}$ genes from baseline.

In patients with hypertension, the changes in Ct values of $\mathrm{E}, \mathrm{RdRP}$, and $\mathrm{N}$ genes from baseline to Day 15,22 , and 29 were significantly greater in clevudine group compared to placebo group (Table 4 and Figure 3; E gene: Day 15: $p=0.0306$, Day 22: $p=0.0543$, Day 29: $p=0.0367$; RdRP gene: Day 15: $p=0.0249$, Day 22: $p=0.0435$, Day 29: $p=0.0111 ; N$ gene: Day 15: $p=0.0212$, Day 22: $p=0.0369$, Day 29: $p=0.0308$ ). Furthermore, the changes in Ct values of $\mathrm{E}, \mathrm{RdRP}$, and $\mathrm{N}$ genes from baseline to Day 15, 22, and 29 were significantly greater in clevudine group compared to placebo group in patients with hypertension and randomized within the first 7 days after the onset of symptoms (Table 5 and Figure 4; E gene; Day 15 
medRxiv preprint doi: https://doi.org/10.1101/2021.12.09.21267566; this version posted December 14, 2021. The copyright holder for this preprint (which was not certified by peer review) is the author/funder, who has granted medRxiv a license to display the preprint in It is made available under a CC-BY-NC-ND 4.0 International license .

$p=0.0080$, Day $22 p=0.0295$, Day $29 p=0.0577$; RdRP gene: Day $15 p=0.0054$, Day 22 $p=0.0202$, Day 29 p=0.0185; N gene: Day $15 p=0.0082$, Day $22 p=0.0187$, Day $29 p=0.0464$ ).

For patients who underwent randomization during the first 5 days after the onset of symptoms and administered clevudine, the change in Ct value of RdRP gene from baseline to Day 29 was significantly greater when compared to placebo (Table 6 and Figure 5; RdRP gene; Day 29 p=0.0565).

In patients who underwent randomization during the first 7 days after the onset of symptoms and administered clevudine, the changes in $\mathrm{Ct}$ value of RdRP and $\mathrm{N}$ genes from baseline to Days 11 and 15 were significantly greater compared to placebo (Table 7 and Figure 6; RdRP gene; Day $11 p=0.0803$, Day $15 p=0.0923 ; N$ gene; Day $11 p=0.0623$, Day 15 $p=0.0393)$.

Proportion of patients who showed improvement in lung involvement

A total of 43 patients had lung involvement at baseline, of which 28 and 15 patients were randomized in clevudine and placebo group, respectively. We evaluated the proportion of patients who showed improvement in lung invasion at Day 29. There was no significant difference in the proportion of patients who showed improvement in lung involvement between clevudine group $(82.14 \%, 23 / 28)$ and placebo group $(100 \%, 15 / 15)$ at Day 29 (Table 8).

Proportion of patients with normal body temperature and normal oxygen saturation

The proportion of patients with normal body temperature and the proportion of patients with normal oxygen saturation at Day 4, 8, 11, 15, 22, and 29 were evaluated, but there was 
medRxiv preprint doi: https://doi.org/10.1101/2021.12.09.21267566; this version posted December 14,2021 . The copyright holder for this preprint (which was not certified by peer review) is the author/funder, who has granted medRxiv a license to display the preprint in It is made available under a CC-BY-NC-ND 4.0 International license .

no significant difference between clevudine group and placebo group at every visit (Table 9, 10).

Changes in CRP from baseline

Changes in CRP from baseline to Day 4, 8, 15, 22, and 29 were evaluated. Clevudine group showed greater decrease in CRP from baseline to all visits than placebo group, but there was no significant difference between clevudine group and placebo group at every visit (Table 11).

Safety and Tolerability

Clevudine and placebo were related with few and low-grade AEs. The incidence of ADRs were $34.15 \%(14 / 41)$ in clevudine group and $30.00 \%(6 / 20)$ in placebo group. There was no significant difference in ADRs occurrence between clevudine group and placebo group $(p=0.7461)$. Five AEs led to discontinuation of clevudine and withdrawal from the study in five patients compared with one $A E$ in one patient for placebo group. Grade 3 or higher $A E$ occurred only in $1.64 \%$ (1/61, hypokalaemia) in the clevudine group and it was resolved. There was no serious $A E$ or fatal outcome in this study. There were no marked differences in results of vital signs, physical examination, electrocardiogram, and laboratory tests between the treatment groups over the 29 days.

\section{Discussion}

The current study found that clevudine was well tolerated but had no significant difference in the proportion of patients with negative result and the clinical efficacy outcomes compared 
medRxiv preprint doi: https://doi.org/10.1101/2021.12.09.21267566; this version posted December 14, 2021. The copyright holder for this preprint (which was not certified by peer review) is the author/funder, who has granted medRxiv a license to display the preprint in It is made available under a CC-BY-NC-ND 4.0 International license

to placebo in COVID-19 patients with moderate severity. However, clevudine was related with antiviral efficacy as evidenced by significant Ct value changes from baseline in patients with moderate COVID-19 and hypertension. The mechanism underlying this efficacy remains unclear. Furthermore, it is reported that antihypertensive drugs and glucose-lowering agents might positively influence the clinical outcomes and disease severity of COVID-19 and the degree of impact is different depending on the class of antihypertensive drugs and glucoselowering agents according to observational retrospective studies. ${ }^{32-34}$ Considering these points, there is a need to draw a firm conclusion considering the effect of patient's underlying diseases and concomitant medication on this result.

In patients randomized within the first 5 and 7 days after onset of symptoms, the greater change from baseline on $\mathrm{Ct}$ values observed in the clevudine group than the placebo group supports the finding that early treatment with clevudine would have an antiviral effect on SARS-CoV-2. Furthermore, more robust antiviral efficacy of clevudine can be expected in consideration of remarkably higher viral load in clevudine group than in placebo group at baseline.

With regard to safety profile, clevudine was well tolerated with no notable significant differences in ADRs or serious AEs between clevudine and placebo. There were no findings on clevudine that were new or not previously known from established safety information in HBV patients.

Based on the results from this study, the clinical use of clevudine in COVID-19 patients is expected to have a favorable outcome by suppressing the infectious virus replication, lowering viral load, and preventing the spread of COVID-19 in early stages of the infection.

\section{Conclusion}


medRxiv preprint doi: https://doi.org/10.1101/2021.12.09.21267566; this version posted December 14, 2021. The copyright holder for this preprint (which was not certified by peer review) is the author/funder, who has granted medRxiv a license to display the preprint in It is made available under a CC-BY-NC-ND 4.0 International license .

This is the first clinical study to compare the antiviral efficacy and safety of clevudine to placebo in Korean COVID-19 patients with moderate severity. The study has demonstrated a possible favorable outcome for the reduction of SARS-CoV-2 replication, with acceptable safety profile, when COVID-19 patients were treated with clevudine. This study further suggested that clevudine can be a favorable treatment option in the clinical practice for patients with moderate COVID-19, especially patients with hypertension. When we designed this study immediately after COVID-19 outbreak, the epidemiological and clinical features of COVID-19 had not been fully understood, therefore, we designed it as an initial therapeutic exploratory study. For this reason, this study had several limitations related to the study design (e.g., single blinded and small patient population, virological assessment as a primary outcome) and an imbalance in viral load at baseline between two treatment groups. Therefore, further large-scale clinical studies, preferably with various clinical endpoints and virus titer evaluation, are required to better understand the effectiveness of using clevudine in COVID19 treatment. However, it is not simple to show a significant effectiveness of antiviral treatments in COVID-19 patients with mild or moderate severity because most of these patients do recover naturally from COVID-19 without any treatments. ${ }^{35}$ Considering this point, we need to design a clinical study aiming for reducing clinical risk of COVID-19 in mild to moderate patients at risk of severe illness when conducting further study.

\section{Funding}

This work was supported by Bukwang Pharm. Co. Ltd. 
medRxiv preprint doi: https://doi.org/10.1101/2021.12.09.21267566; this version posted December 14, 2021. The copyright holder for this preprint (which was not certified by peer review) is the author/funder, who has granted medRxiv a license to display the preprint in

\section{References}

1. WHO Director-General's opening remarks at the media briefing on COVID19 -March 2020. WHO, 2020. (Accessed Oct-7-2021, at https://www.who.int/directorgeneral/speeches/detail/who-director-general-s-opening-remarks-at-the-media-briefingon-covid-19---11-march-2020.)

2. Zeng $\mathrm{H}$, Ma Y, Zhou Z, et al. Spectrum and Clinical Characteristics of Symptomatic and Asymptomatic Coronavirus Disease 2019 (COVID-19) With and Without Pneumonia. Front Med (Lausanne) 2021;8:645651.

3. Sadie S, Sarah H, Rahayma S, Jennifer L, Michael P, Anna S. The Impact of Age, Sex, and Race on the Association of Risk Factors and Mortality in COVID-19 Patients. Journal of Infectious Diseases and Epidemiology 2021;7:215.

4. Navar AM, Purinton SN, Hou Q, Taylor RJ, Peterson ED. The impact of race and ethnicity on outcomes in 19,584 adults hospitalized with COVID-19. PLoS One 2021;16:e0254809.

5. Alam MR, Kabir MR, Reza S. Comorbidities might be a risk factor for the incidence of COVID-19: Evidence from a web-based survey. Prev Med Rep 2021;21:101319.

6. Yang J, Zheng Y, Gou X, et al. Prevalence of comorbidities and its effects in patients infected with SARS-CoV-2: a systematic review and meta-analysis. Int J Infect Dis 2020;94:91-5.

7. Ji W, Huh K, Kang M, et al. Effect of Underlying Comorbidities on the Infection and Severity of COVID-19 in Korea: a Nationwide Case-Control Study. J Korean Med Sci 2020;35:e237.

8. Jang S, Rhee JY, Wi YM, Jung BK. Viral kinetics of SARS-CoV-2 over the preclinical, clinical, and postclinical period. Int $\mathrm{J}$ Infect Dis 2021;102:561-5.

9. Suh HJ, Kim DH, Heo EY, et al. Clinical Characteristics of COVID-19: Clinical Dynamics of Mild Severe Acute Respiratory Syndrome Coronavirus 2 Infection Detected by Early Active Surveillance. J Korean Med Sci 2020;35:e297.

10. Gentilotti E, Savoldi A, Compri M, et al. Assessment of COVID-19 progression on day 5 from symptoms onset. BMC Infect Dis 2021;21:883. 
medRxiv preprint doi: https://doi.org/10.1101/2021.12.09.21267566; this version posted December 14, 2021. The copyright holder for this preprint (which was not certified by peer review) is the author/funder, who has granted medRxiv a license to display the preprint in It is made available under a CC-BY-NC-ND 4.0 International license

11. Lee YH, Hong CM, Kim DH, Lee TH, Lee J. Clinical Course of Asymptomatic and Mildly Symptomatic Patients with Coronavirus Disease Admitted to Community Treatment Centers, South Korea. Emerg Infect Dis 2020;26:2346-52.

12. Malik S, Gupta A, Zhong X, Rasmussen TP, Manautou JE, Bahal R. Emerging Therapeutic Modalities against COVID-19. Pharmaceuticals (Basel) 2020;13.

13. Wang Y, Zhang D, Du G, et al. Remdesivir in adults with severe COVID-19: a randomised, double-blind, placebo-controlled, multicentre trial. Lancet 2020;395:1569-78.

14. Kokic G, Hillen HS, Tegunov D, et al. Mechanism of SARS-CoV-2 polymerase stalling by remdesivir. Nat Commun 2021;12:279.

15. Gurung AB, Ali MA, Lee J, Farah MA, Al-Anazi KM. The potential of Paritaprevir and Emetine as inhibitors of SARS-CoV-2 RdRp. Saudi J Biol Sci 2021;28:1426-32.

16. Udwadia ZF, Singh P, Barkate H, et al. Efficacy and safety of favipiravir, an oral RNAdependent RNA polymerase inhibitor, in mild-to-moderate COVID-19: A randomized, comparative, open-label, multicenter, phase 3 clinical trial. Int $\mathrm{J}$ Infect Dis 2021;103:62-71.

17. Furuta Y, Komeno T, Nakamura T. Favipiravir (T-705), a broad spectrum inhibitor of viral RNA polymerase. Proc Jpn Acad Ser B Phys Biol Sci 2017;93:449-63.

18. Arabi YM, Gordon AC, Derde LPG, et al. Lopinavir-ritonavir and hydroxychloroquine for critically ill patients with COVID-19: REMAP-CAP randomized controlled trial. Intensive Care Med 2021;47:867-86.

19. Sisay M. $3 \mathrm{CL}$ (pro) inhibitors as a potential therapeutic option for COVID-19: Available evidence and ongoing clinical trials. Pharmacol Res 2020;156:104779.

20. Mody V, Ho J, Wills S, et al. Identification of 3-chymotrypsin like protease (3CLPro) inhibitors as potential anti-SARS-CoV-2 agents. Commun Biol 2021;4:93.

21. Breining P, Frølund AL, Højen JF, et al. Camostat mesylate against SARS-CoV-2 and COVID-19-Rationale, dosing and safety. Basic Clin Pharmacol Toxicol 2021;128:204-12.

22. Halford S, Wan S, Dragoni I, et al. SPIKE-1: A Randomised Phase II/III trial in a community 
medRxiv preprint doi: https://doi.org/10.1101/2021.12.09.21267566; this version posted December 14, 2021. The copyright holder for this preprint (which was not certified by peer review) is the author/funder, who has granted medRxiv a license to display the preprint in It is made available under a CC-BY-NC-ND 4.0 International license .

setting, assessing use of camostat in reducing the clinical progression of COVID-19 by blocking SARS-CoV-2 Spike protein-initiated membrane fusion. Trials 2021;22:550.

23. Lescure FX, Bouadma L, Nguyen D, et al. Clinical and virological data of the first cases of COVID-19 in Europe: a case series. Lancet Infect Dis 2020;20:697-706.

24. Zhou F, Yu T, Du R, et al. Clinical course and risk factors for mortality of adult inpatients with COVID-19 in Wuhan, China: a retrospective cohort study. Lancet 2020;395:1054-62.

25. Wing PA, Davenne T, Wettengel J, et al. A dual role for SAMHD1 in regulating HBV cccDNA and RT-dependent particle genesis. Life Sci Alliance 2019;2.

26. Jones SA, Murakami E, Delaney W, Furman P, Hu J. Noncompetitive inhibition of hepatitis $B$ virus reverse transcriptase protein priming and DNA synthesis by the nucleoside analog clevudine. Antimicrob Agents Chemother 2013;57:4181-9.

27. Hui CK, Lau GK. Clevudine for the treatment of chronic hepatitis B virus infection. Expert Opin Investig Drugs 2005;14:1277-84.

28. Chhetri A, Brahman D. Molecular Docking Study of Some Nucleoside Analogs against Main Protease of SARS-CoV-2. 2020.

29. My TTA, Hieu LT, Hai NTT, et al. Study on SARS-CoV-2 inhibition of some potential drugs using molecular docking simulation. Vietnam Journal of Chemistry 2020;58:666-74.

30. Tom MR, Mina MJ. To Interpret the SARS-CoV-2 Test, Consider the Cycle Threshold Value. Clin Infect Dis 2020;71:2252-4.

31. Rao SN, Manissero D, Steele VR, Pareja J. A Systematic Review of the Clinical Utility of Cycle Threshold Values in the Context of COVID-19. Infect Dis Ther 2020;9:573-86.

32. Yan F, Huang F, Xu J, et al. Antihypertensive drugs are associated with reduced fatal outcomes and improved clinical characteristics in elderly COVID-19 patients. Cell Discov 2020;6:77.

33. Semenzato L, Botton J, Drouin J, et al. Antihypertensive Drugs and COVID-19 Risk: A Cohort Study of 2 Million Hypertensive Patients. Hypertension 2021;77:833-42. 
medRxiv preprint doi: https://doi.org/10.1101/2021.12.09.21267566; this version posted December 14,2021 . The copyright holder for this preprint (which was not certified by peer review) is the author/funder, who has granted medRxiv a license to display the preprint in It is made available under a CC-BY-NC-ND 4.0 International license

34. Scheen AJ. Metformin and COVID-19: From cellular mechanisms to reduced mortality. Diabetes Metab 2020;46:423-6.

35. Şimşek Yavuz S, Ünal S. Antiviral treatment of COVID-19. Turk J Med Sci 2020;50:611-9. 
medRxiv preprint doi: https://doi.org/10.1101/2021.12.09.21267566; this version posted December 14,2021 . The copyright holder for this preprint (which was not certified by peer review) is the author/funder, who has granted medRxiv a license to display the preprint in It is made available under a CC-BY-NC-ND 4.0 International license

Table 1. Baseline characteristics of the patients.

\begin{tabular}{|c|c|c|c|c|}
\hline & & $\begin{array}{c}\text { Clevudine } \\
(\mathrm{N}=41)\end{array}$ & $\begin{array}{l}\text { Placebo } \\
(\mathrm{N}=20)\end{array}$ & $\begin{array}{c}\text { Total } \\
(\mathrm{N}=61)\end{array}$ \\
\hline \multirow[t]{3}{*}{ Age } & Mean \pm Std & $60.02 \pm 13.44$ & $59.50 \pm 11.69$ & $59.85 \pm 12.80$ \\
\hline & Median & 63.00 & 60.00 & 61.00 \\
\hline & Min Max & $24.00 \sim 81.00$ & $36.00 \sim 74.00$ & $24.00 \sim 81.00$ \\
\hline \multirow[t]{2}{*}{ Gender } & Male & $20(48.78 \%)$ & $10(50.00 \%)$ & $30(49.18 \%)$ \\
\hline & Female & $21(51.22 \%)$ & $10(50.00 \%)$ & $31(50.82 \%)$ \\
\hline \multirow[t]{5}{*}{ Symptoms of COVID-19 } & Fever & $39(95.12 \%)$ & $16(80.00 \%)$ & $55(90.16 \%)$ \\
\hline & Cough & $23(56.10 \%)$ & $17(85.00 \%)$ & $40(65.57 \%)$ \\
\hline & Myalgia & $19(46.34 \%)$ & $8(40.00 \%)$ & $27(44.26 \%)$ \\
\hline & Headache & $16(39.02 \%)$ & $11(55.00 \%)$ & $27(44.26 \%)$ \\
\hline & Sore throat & $15(36.59 \%)$ & $9(45.00 \%)$ & $24(39.34 \%)$ \\
\hline Day from symptom onset to & $1 \sim 5$ & $21(51.22 \%)$ & $13(65.00 \%)$ & $34(55.74 \%)$ \\
\hline randomization & $1 \sim 7$ & $32(78.05 \%)$ & $17(85.00 \%)$ & $49(80.33 \%)$ \\
\hline \multirow[t]{3}{*}{ Comorbidity } & Hypertension & $19(46.34 \%)$ & $9(45.00 \%)$ & $28(45.90 \%)$ \\
\hline & Diabetes mellitus & $13(31.71 \%)$ & $3(15.00 \%)$ & $16(26.23 \%)$ \\
\hline & Hyperlipidemia & $5(12.20 \%)$ & $3(15.00 \%)$ & $8(13.11 \%)$ \\
\hline
\end{tabular}


medRxiv preprint doi: https://doi.org/10.1101/2021.12.09.21267566; this version posted December 14,2021 . The copyright holder for this preprint (which was not certified by peer review) is the author/funder, who has granted medRxiv a license to display the preprint in It is made available under a CC-BY-NC-ND 4.0 International license

Table 2. Proportion of patients with real-time RT-PCR negative test result (ITT set)

\begin{tabular}{|c|c|c|c|c|}
\hline & & $\begin{array}{c}\text { Clevudine } \\
(\mathrm{N}=41)\end{array}$ & $\begin{array}{c}\text { Placebo } \\
(\mathrm{N}=20)\end{array}$ & $\begin{array}{c}\text { Total } \\
(\mathrm{N}=61)\end{array}$ \\
\hline \multirow[t]{4}{*}{ Day4 } & Negative & $0(0.00 \%)$ & $0(0.00 \%)$ & $0(0.00 \%)$ \\
\hline & Positive & $39(100.00 \%)$ & $20(100.00 \%)$ & $59(100.00 \%)$ \\
\hline & Total & $39(66.10 \%)$ & $20(33.90 \%)$ & $59(100.00 \%)$ \\
\hline & P-value & \multicolumn{2}{|c|}{-} & \\
\hline \multirow[t]{4}{*}{ Day8 } & Negative & $0(0.00 \%)$ & $0(0.00 \%)$ & $0(0.00 \%)$ \\
\hline & Positive & $39(100.00 \%)$ & $20(100.00 \%)$ & $59(100.00 \%)$ \\
\hline & Total & $39(66.10 \%)$ & $20(33.90 \%)$ & $59(100.00 \%)$ \\
\hline & P-value & \multicolumn{2}{|c|}{ 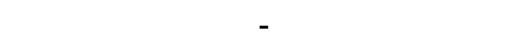 } & \\
\hline \multirow[t]{4}{*}{ Day11 } & Negative & $4(10.26 \%)$ & $2(10.00 \%)$ & $6(10.17 \%)$ \\
\hline & Positive & $35(89.74 \%)$ & $18(90.00 \%)$ & $53(89.83 \%)$ \\
\hline & Total & $39(66.10 \%)$ & $20(33.90 \%)$ & $59(100.00 \%)$ \\
\hline & P-value & \multicolumn{2}{|c|}{$>.9999 \ddagger$} & \\
\hline \multirow[t]{4}{*}{ Day15 } & Negative & $10(25.64 \%)$ & $5(25.00 \%)$ & $15(25.42 \%)$ \\
\hline & Positive & $29(74.36 \%)$ & $15(75.00 \%)$ & $44(74.58 \%)$ \\
\hline & Total & $39(66.10 \%)$ & $20(33.90 \%)$ & $59(100.00 \%)$ \\
\hline & P-value & \multicolumn{2}{|c|}{$0.9573 \dagger$} & \\
\hline \multirow[t]{4}{*}{ Day22 } & Negative & $19(48.72 \%)$ & $12(60.00 \%)$ & $31(52.54 \%)$ \\
\hline & Positive & $20(51.28 \%)$ & $8(40.00 \%)$ & $28(47.46 \%)$ \\
\hline & Total & $39(66.10 \%)$ & $20(33.90 \%)$ & $59(100.00 \%)$ \\
\hline & P-value & \multicolumn{2}{|c|}{$0.4114 \dagger$} & \\
\hline \multirow[t]{4}{*}{ Day29 } & Negative & $27(69.23 \%)$ & $12(60.00 \%)$ & $39(66.10 \%)$ \\
\hline & Positive & $12(30.77 \%)$ & $8(40.00 \%)$ & $20(33.90 \%)$ \\
\hline & Total & $39(66.10 \%)$ & $20(33.90 \%)$ & $59(100.00 \%)$ \\
\hline & $\mathrm{P}$-value & \multicolumn{2}{|c|}{$0.4783 \dagger$} & \\
\hline
\end{tabular}

Note) †: Pearson's chi-square test, $\ddagger$ : Fisher's exact test 
Table 3. Change in Ct value from baseline (ITT set)

\begin{tabular}{|c|c|c|c|c|c|c|c|}
\hline & & \multicolumn{2}{|c|}{ E gene } & \multicolumn{2}{|c|}{ RdRP gene } & \multicolumn{2}{|c|}{$\mathrm{N}$ gene } \\
\hline & & $\begin{array}{c}\text { Clevudine } \\
(\mathrm{N}=41)\end{array}$ & $\begin{array}{l}\text { Placebo } \\
(\mathrm{N}=20)\end{array}$ & $\begin{array}{c}\text { Clevudine } \\
(\mathrm{N}=41)\end{array}$ & $\begin{array}{l}\text { Placebo } \\
(\mathrm{N}=20)\end{array}$ & $\begin{array}{c}\text { Clevudine } \\
(\mathrm{N}=41)\end{array}$ & $\begin{array}{l}\text { Placebo } \\
(\mathrm{N}=20)\end{array}$ \\
\hline \multirow[t]{5}{*}{ Baseline } & $\mathrm{N}$ & 39 & 20 & 39 & 20 & 39 & 20 \\
\hline & Mean \pm Std & $21.57 \pm 6.76$ & $24.72 \pm 6.51$ & $22.45 \pm 6.29$ & $25.35 \pm 5.55$ & $23.55 \pm 6.29$ & $25.96 \pm 5.27$ \\
\hline & Median & 21.05 & 23.09 & 21.91 & 24.55 & 23.27 & 25.71 \\
\hline & Min Max & $11.07 \sim 40.00$ & $11.87 \sim 40.00$ & $13.01 \sim 36.45$ & $13.65 \sim 37.05$ & $14.57 \sim 40.00$ & $11.91 \sim 35.84$ \\
\hline & P-value & \multicolumn{2}{|c|}{$0.0928^{*}$} & \multicolumn{2}{|c|}{$0.0862^{*}$} & \multicolumn{2}{|c|}{$0.1469^{*}$} \\
\hline \multirow[t]{5}{*}{ Day4 } & $\mathrm{N}$ & 39 & 20 & 39 & 20 & 39 & 20 \\
\hline & Mean \pm Std & $27.02 \pm 6.68$ & $29.89 \pm 7.05$ & $27.66 \pm 6.03$ & $29.52 \pm 5.59$ & $27.91 \pm 5.22$ & $29.64 \pm 5.05$ \\
\hline & Median & 27.03 & 27.20 & 28.08 & 28.29 & 28.38 & 29.02 \\
\hline & Min Max & $15.38 \sim 40.00$ & $20.72 \sim 40.00$ & $15.26 \sim 40.00$ & $20.26 \sim 40.00$ & $15.55 \sim 35.81$ & $20.36 \sim 38.83$ \\
\hline & P-value & \multicolumn{2}{|c|}{$0.2436 ¥$} & \multicolumn{2}{|c|}{$0.2556^{*}$} & \multicolumn{2}{|c|}{$0.2271^{*}$} \\
\hline \multirow[t]{5}{*}{ Day8 } & $\mathrm{N}$ & 36 & 18 & 36 & 18 & 36 & 18 \\
\hline & Mean \pm Std & $32.35 \pm 6.50$ & $35.05 \pm 5.84$ & $32.02 \pm 5.24$ & $34.16 \pm 5.03$ & $32.04 \pm 4.59$ & $34.04 \pm 4.77$ \\
\hline & Median & 32.94 & 38.23 & 33.62 & 34.79 & 33.32 & 34.67 \\
\hline & Min Max & $19.28 \sim 40.00$ & $24.69 \sim 40.00$ & $20.28 \sim 40.00$ & $23.31 \sim 40.00$ & $22.68 \sim 40.00$ & $24.00 \sim 40.00$ \\
\hline & P-value & \multicolumn{2}{|c|}{$0.1766 \mp$} & \multicolumn{2}{|c|}{$0.1572^{*}$} & \multicolumn{2}{|c|}{$0.1422^{*}$} \\
\hline \multirow[t]{5}{*}{ Day11 } & $\mathrm{N}$ & 31 & 18 & 31 & 18 & 31 & 18 \\
\hline & Mean \pm Std & $35.95 \pm 5.38$ & $35.22 \pm 4.87$ & $35.35 \pm 4.61$ & $34.30 \pm 4.36$ & $35.15 \pm 4.12$ & $33.76 \pm 3.88$ \\
\hline & Median & 40.00 & 34.98 & 36.51 & 33.46 & 35.42 & 33.33 \\
\hline & Min Max & $24.17 \sim 40.00$ & $25.76 \sim 40.00$ & $25.67 \sim 40.00$ & $26.71 \sim 40.00$ & $26.40 \sim 40.00$ & $27.95 \sim 40.00$ \\
\hline & P-value & \multicolumn{2}{|c|}{$0.5997 ¥$} & \multicolumn{2}{|c|}{$0.4144 ¥$} & \multicolumn{2}{|c|}{$0.2296 ¥$} \\
\hline \multirow[t]{5}{*}{ Day15 } & $\mathrm{N}$ & 34 & 18 & 34 & 18 & 34 & 18 \\
\hline & Mean \pm Std & $36.73 \pm 5.47$ & $36.81 \pm 4.60$ & $36.76 \pm 4.92$ & $36.41 \pm 4.28$ & $36.49 \pm 4.61$ & $35.24 \pm 4.28$ \\
\hline & Median & 40.00 & 40.00 & 40.00 & 38.55 & 37.46 & 35.33 \\
\hline & Min Max & $16.29 \sim 40.00$ & $24.90 \sim 40.00$ & $18.13 \sim 40.00$ & $26.91 \sim 40.00$ & $19.31 \sim 40.00$ & $26.24 \sim 40.00$ \\
\hline & P-value & \multicolumn{2}{|c|}{$0.8784 ¥$} & \multicolumn{2}{|c|}{$0.6501 ¥$} & \multicolumn{2}{|c|}{$0.1983 ¥$} \\
\hline
\end{tabular}




\begin{tabular}{|c|c|c|c|c|c|c|c|}
\hline & & \multicolumn{2}{|c|}{ E gene } & \multicolumn{2}{|c|}{ RdRP gene } & \multicolumn{2}{|c|}{$\mathrm{N}$ gene } \\
\hline & & $\begin{array}{c}\text { Clevudine } \\
(\mathrm{N}=41)\end{array}$ & $\begin{array}{l}\text { Placebo } \\
(\mathrm{N}=20)\end{array}$ & $\begin{array}{c}\text { Clevudine } \\
(\mathrm{N}=41)\end{array}$ & $\begin{array}{l}\text { Placebo } \\
(\mathrm{N}=20)\end{array}$ & $\begin{array}{c}\text { Clevudine } \\
(\mathrm{N}=41)\end{array}$ & $\begin{array}{l}\text { Placebo } \\
(\mathrm{N}=20)\end{array}$ \\
\hline \multirow[t]{5}{*}{ Day22 } & $\mathrm{N}$ & 30 & 18 & 30 & 18 & 30 & 18 \\
\hline & Mean \pm Std & $38.69 \pm 2.78$ & $39.82 \pm 0.76$ & $38.60 \pm 2.75$ & $39.44 \pm 1.39$ & $38.48 \pm 2.60$ & $38.77 \pm 2.33$ \\
\hline & Median & 40.00 & 40.00 & 40.00 & 40.00 & 40.00 & 40.00 \\
\hline & Min Max & $31.40 \sim 40.00$ & $36.76 \sim 40.00$ & $31.69 \sim 40.00$ & $35.69 \sim 40.00$ & $32.35 \sim 40.00$ & $31.76 \sim 40.00$ \\
\hline & P-value & \multicolumn{2}{|c|}{$0.1566 ¥$} & \multicolumn{2}{|c|}{$0.4751 ¥$} & \multicolumn{2}{|c|}{$0.7920 ¥$} \\
\hline \multirow[t]{5}{*}{ Day29 } & $\mathrm{N}$ & 32 & 17 & 32 & 17 & 32 & 17 \\
\hline & Mean \pm Std & $39.30 \pm 2.24$ & $39.66 \pm 1.42$ & $39.47 \pm 2.07$ & $39.43 \pm 1.80$ & $39.20 \pm 2.35$ & $39.32 \pm 1.85$ \\
\hline & Median & 40.00 & 40.00 & 40.00 & 40.00 & 40.00 & 40.00 \\
\hline & Min Max & $31.43 \sim 40.00$ & $34.16 \sim 40.00$ & $31.50 \sim 40.00$ & $32.91 \sim 40.00$ & $30.77 \sim 40.00$ & $33.42 \sim 40.00$ \\
\hline & P-value & \multicolumn{2}{|c|}{$0.6444 ¥$} & \multicolumn{2}{|c|}{$0.5829 ¥$} & \multicolumn{2}{|c|}{$0.6932 ¥$} \\
\hline Day4 - Baseline & $\mathrm{N}$ & 39 & 20 & 39 & 20 & 39 & 20 \\
\hline \multirow[t]{5}{*}{ (Change) } & Mean \pm Std & $5.45 \pm 4.43$ & $5.18 \pm 7.01$ & $5.22 \pm 4.04$ & $4.17 \pm 5.81$ & $4.36 \pm 4.28$ & $3.68 \pm 5.58$ \\
\hline & Median & 5.57 & 4.90 & 5.87 & 5.15 & 4.50 & 3.99 \\
\hline & Min Max & $-4.74 \sim 16.48$ & $-17.13 \sim 17.33$ & $-4.92 \sim 14.66$ & $-14.99 \sim 12.89$ & $-6.01 \sim 13.79$ & $-14.68 \sim 13.09$ \\
\hline & P-value (within) & $<.0001 \#$ & $0.0009 \$$ & $<.0001 \#$ & $0.0017 \$$ & $<.0001 \#$ & $0.0012 \$$ \\
\hline & P-value (between) & \multicolumn{2}{|c|}{$0.9619 ¥$} & \multicolumn{2}{|c|}{$0.4405 ¥$} & \multicolumn{2}{|c|}{$0.6613 ¥$} \\
\hline Day8 - Baseline & $\mathrm{N}$ & 36 & 18 & 36 & 18 & 36 & 18 \\
\hline \multirow[t]{5}{*}{ (Change) } & Mean \pm Std & $10.60 \pm 6.87$ & $10.97 \pm 4.71$ & $9.43 \pm 6.18$ & $9.27 \pm 4.40$ & $8.34 \pm 6.13$ & $8.48 \pm 3.60$ \\
\hline & Median & 10.88 & 12.62 & 9.31 & 9.09 & 8.51 & 8.50 \\
\hline & Min Max & $-1.78 \sim 24.34$ & $3.08 \sim 17.33$ & $-1.72 \sim 21.02$ & $3.27 \sim 16.24$ & $-6.72 \sim 19.12$ & $3.86 \sim 14.26$ \\
\hline & P-value (within) & $<.0001 \#$ & $<.0001 \#$ & $<.0001 \#$ & $<.0001 \#$ & $<.0001 \#$ & $<.0001 \#$ \\
\hline & P-value (between) & \multicolumn{2}{|c|}{$0.8378^{*}$} & \multicolumn{2}{|c|}{$0.9225^{*}$} & \multicolumn{2}{|c|}{$0.9188^{*}$} \\
\hline
\end{tabular}




\begin{tabular}{|c|c|c|c|c|c|c|c|}
\hline & & \multicolumn{2}{|c|}{ E gene } & \multicolumn{2}{|c|}{ RdRP gene } & \multicolumn{2}{|c|}{$\mathrm{N}$ gene } \\
\hline & & $\begin{array}{c}\text { Clevudine } \\
(\mathrm{N}=41)\end{array}$ & $\begin{array}{l}\text { Placebo } \\
(\mathrm{N}=20)\end{array}$ & $\begin{array}{c}\text { Clevudine } \\
(\mathrm{N}=41)\end{array}$ & $\begin{array}{l}\text { Placebo } \\
(\mathrm{N}=20)\end{array}$ & $\begin{array}{c}\text { Clevudine } \\
\quad(\mathrm{N}=41)\end{array}$ & $\begin{array}{l}\text { Placebo } \\
(\mathrm{N}=20)\end{array}$ \\
\hline Day11 - Baseline & $\mathrm{N}$ & 31 & 18 & 31 & 18 & 31 & 18 \\
\hline \multirow[t]{5}{*}{ (Change) } & Mean \pm Std & $13.70 \pm 7.57$ & $11.14 \pm 7.50$ & $12.39 \pm 6.68$ & $9.41 \pm 6.60$ & $10.99 \pm 6.59$ & $8.19 \pm 6.44$ \\
\hline & Median & 12.40 & 12.18 & 11.31 & 9.08 & 9.85 & 7.49 \\
\hline & Min Max & $0.00 \sim 27.74$ & $-2.69 \sim 28.13$ & $0.23 \sim 25.97$ & $-2.56 \sim 19.06$ & $-5.21 \sim 24.27$ & $-3.33 \sim 22.01$ \\
\hline & P-value (within) & $<.0001 \#$ & $<.0001 \#$ & $<.0001 \#$ & $<.0001 \#$ & $<.0001 \#$ & $<.0001 \#$ \\
\hline & P-value (between) & \multicolumn{2}{|c|}{$0.2568^{*}$} & \multicolumn{2}{|c|}{$0.1386^{*}$} & \multicolumn{2}{|c|}{$0.1541^{*}$} \\
\hline Day15 - Baseline & $\mathrm{N}$ & 34 & 18 & 34 & 18 & 34 & 18 \\
\hline \multirow[t]{5}{*}{ (Change) } & Mean \pm Std & $14.83 \pm 8.67$ & $12.73 \pm 6.88$ & $13.95 \pm 7.86$ & $11.52 \pm 6.24$ & $12.55 \pm 7.89$ & $9.67 \pm 5.63$ \\
\hline & Median & 15.02 & 13.62 & 13.44 & 12.44 & 12.59 & 9.52 \\
\hline & Min Max & $-5.32 \sim 28.93$ & $-1.59 \sim 24.06$ & $-4.49 \sim 25.60$ & $-1.03 \sim 22.84$ & $-5.95 \sim 24.63$ & $-1.95 \sim 20.15$ \\
\hline & P-value (within) & $<.0001 \#$ & $<.0001 \#$ & $<.0001 \#$ & $<.0001 \#$ & $<.0001 \#$ & $<.0001 \#$ \\
\hline & P-value (between) & \multicolumn{2}{|c|}{$0.3784^{*}$} & \multicolumn{2}{|c|}{$0.2612^{*}$} & \multicolumn{2}{|c|}{$0.1765^{\star}$} \\
\hline Day22 - Baseline & $\mathrm{N}$ & 30 & 18 & 30 & 18 & 30 & 18 \\
\hline \multirow[t]{5}{*}{ (Change) } & Mean \pm Std & $16.65 \pm 7.73$ & $15.74 \pm 5.32$ & $15.69 \pm 7.18$ & $14.55 \pm 4.98$ & $14.39 \pm 7.35$ & $13.20 \pm 5.06$ \\
\hline & Median & 16.75 & 16.91 & 16.45 & 15.46 & 14.50 & 13.77 \\
\hline & Min Max & $0.00 \sim 28.16$ & $5.08 \sim 24.89$ & $1.21 \sim 25.97$ & $3.79 \sim 22.84$ & $-4.18 \sim 24.63$ & $0.30 \sim 23.12$ \\
\hline & P-value (within) & $<.0001 \#$ & $<.0001 \#$ & $<.0001 \#$ & $<.0001 \#$ & $<.0001 \#$ & $<.0001 \#$ \\
\hline & P-value (between) & \multicolumn{2}{|c|}{$0.6623^{*}$} & \multicolumn{2}{|c|}{$0.5563^{*}$} & \multicolumn{2}{|c|}{$0.5472^{*}$} \\
\hline Day29 - Baseline & $\mathrm{N}$ & 32 & 17 & 32 & 17 & 32 & 17 \\
\hline \multirow[t]{5}{*}{ (Change) } & Mean \pm Std & $17.63 \pm 7.27$ & $16.11 \pm 4.73$ & $16.96 \pm 6.65$ & $14.95 \pm 4.06$ & $15.51 \pm 6.69$ & $14.16 \pm 3.80$ \\
\hline & Median & 16.22 & 16.96 & 16.79 & 15.71 & 13.84 & 14.26 \\
\hline & Min Max & $0.00 \sim 28.93$ & $5.08 \sim 24.06$ & $3.55 \sim 26.99$ & $5.75 \sim 22.84$ & $0.00 \sim 25.43$ & 7.17 21.67 \\
\hline & P-value (within) & $<.0001 \#$ & $<.0001 \#$ & $<.0001 \#$ & $<.0001 \#$ & $<.0001 \#$ & $<.0001 \#$ \\
\hline & P-value (between) & \multicolumn{2}{|c|}{$0.4433^{*}$} & \multicolumn{2}{|c|}{$0.1973^{*}$} & \multicolumn{2}{|c|}{$0.3729^{*}$} \\
\hline
\end{tabular}

Note) *: Two sample t-test, $¥:$ Wilcoxon's rank sum test, \#: Paired t-test, \$: Wilcoxon’s signed rank test 
Table 4. Change in Ct value from baseline (patients with hypertension, ITT set)

\begin{tabular}{|c|c|c|c|c|c|c|c|}
\hline & & \multicolumn{2}{|c|}{ E gene } & \multicolumn{2}{|c|}{ RdRP gene } & \multicolumn{2}{|c|}{$\mathrm{N}$ gene } \\
\hline & & $\begin{array}{l}\text { Clevudine } \\
(\mathrm{N}=19)\end{array}$ & $\begin{array}{l}\text { Placebo } \\
(\mathrm{N}=9)\end{array}$ & $\begin{array}{l}\text { Clevudine } \\
(\mathrm{N}=19)\end{array}$ & $\begin{array}{c}\text { Placebo } \\
(\mathrm{N}=9)\end{array}$ & $\begin{array}{l}\text { Clevudine } \\
(\mathrm{N}=19)\end{array}$ & $\begin{array}{c}\text { Placebo } \\
(\mathrm{N}=9)\end{array}$ \\
\hline \multirow[t]{5}{*}{ Baseline } & $\mathrm{N}$ & 19 & 9 & 19 & 9 & 19 & 9 \\
\hline & Mean \pm Std & $18.66 \pm 4.31$ & $24.45 \pm 6.86$ & $19.83 \pm 3.70$ & $25.13 \pm 6.17$ & $20.88 \pm 3.61$ & $25.37 \pm 6.12$ \\
\hline & Median & 19.63 & 23.14 & 20.18 & 24.83 & 20.80 & 26.39 \\
\hline & Min Max & $11.84 \sim 25.35$ & $11.87 \sim 34.92$ & $14.40 \sim 26.38$ & $13.65 \sim 34.25$ & 15.37 27.54 & $11.91 \sim 32.83$ \\
\hline & P-value & \multicolumn{2}{|c|}{$0.0110^{*}$} & \multicolumn{2}{|c|}{$0.0085^{*}$} & \multicolumn{2}{|c|}{$0.0214^{*}$} \\
\hline \multirow[t]{5}{*}{ Day4 } & $\mathrm{N}$ & 19 & 9 & 19 & 9 & 19 & 9 \\
\hline & Mean \pm Std & $23.89 \pm 5.18$ & $30.64 \pm 7.87$ & $25.05 \pm 4.99$ & $29.51 \pm 6.29$ & $25.56 \pm 4.74$ & $29.42 \pm 5.37$ \\
\hline & Median & 24.50 & 33.25 & 24.45 & 32.77 & 25.33 & 31.14 \\
\hline & Min Max & $15.38 \sim 32.14$ & $20.72 \sim 40.00$ & $15.26 \sim 31.99$ & $20.26 \sim 36.45$ & $15.55 \sim 32.50$ & $20.36 \sim 35.13$ \\
\hline & P-value & \multicolumn{2}{|c|}{$0.0115^{*}$} & \multicolumn{2}{|c|}{$0.0521^{*}$} & \multicolumn{2}{|c|}{$0.0649^{*}$} \\
\hline \multirow[t]{5}{*}{ Day8 } & $\mathrm{N}$ & 17 & 9 & 17 & 9 & 17 & 9 \\
\hline & Mean \pm Std & $30.96 \pm 6.59$ & $35.93 \pm 6.00$ & $30.86 \pm 5.51$ & $33.65 \pm 5.62$ & $31.07 \pm 4.85$ & $33.18 \pm 4.55$ \\
\hline & Median & 31.12 & 40.00 & 31.65 & 34.86 & 32.58 & 34.74 \\
\hline & Min Max & $19.28 \sim 40.00$ & $24.69 \sim 40.00$ & $20.28 \sim 40.00$ & $23.31 \sim 40.00$ & $22.68 \sim 40.00$ & $24.00 \sim 37.42$ \\
\hline & P-value & \multicolumn{2}{|c|}{$0.0952 ¥$} & \multicolumn{2}{|c|}{$0.2357^{*}$} & \multicolumn{2}{|c|}{$0.2684 ¥$} \\
\hline \multirow[t]{5}{*}{ Day11 } & $\mathrm{N}$ & 13 & 9 & 13 & 9 & 13 & 9 \\
\hline & Mean \pm Std & $33.17 \pm 5.95$ & $35.21 \pm 4.74$ & $32.87 \pm 4.87$ & $33.89 \pm 4.30$ & $32.68 \pm 4.07$ & $32.91 \pm 4.05$ \\
\hline & Median & 32.48 & 34.26 & 33.52 & 32.71 & 32.87 & 33.27 \\
\hline & Min Max & $24.17 \sim 40.00$ & $29.30 \sim 40.00$ & $25.67 \sim 40.00$ & $28.49 \sim 40.00$ & $26.40 \sim 40.00$ & $28.13 \sim 40.00$ \\
\hline & P-value & \multicolumn{2}{|c|}{$0.4208 ¥$} & \multicolumn{2}{|c|}{$0.6202^{*}$} & \multicolumn{2}{|c|}{$0.8995^{*}$} \\
\hline \multirow[t]{5}{*}{ Day15 } & $\mathrm{N}$ & 15 & 9 & 15 & 9 & 15 & 9 \\
\hline & Mean \pm Std & $37.21 \pm 4.68$ & $35.93 \pm 4.07$ & $37.07 \pm 4.06$ & $35.70 \pm 4.28$ & $37.08 \pm 3.81$ & $34.69 \pm 4.40$ \\
\hline & Median & 40.00 & 35.89 & 38.80 & 35.42 & 37.36 & 33.97 \\
\hline & Min Max & $24.49 \sim 40.00$ & $31.37 \sim 40.00$ & $25.82 \sim 40.00$ & $30.87 \sim 40.00$ & $26.80 \sim 40.00$ & $29.51 \sim 40.00$ \\
\hline & P-value & \multicolumn{2}{|c|}{$0.3610 ¥$} & \multicolumn{2}{|c|}{$0.4234 ¥$} & \multicolumn{2}{|c|}{$0.1964 ¥$} \\
\hline
\end{tabular}




\begin{tabular}{|c|c|c|c|c|c|c|c|}
\hline & & \multicolumn{2}{|c|}{ E gene } & \multicolumn{2}{|c|}{ RdRP gene } & \multicolumn{2}{|c|}{$\mathrm{N}$ gene } \\
\hline & & $\begin{array}{l}\text { Clevudine } \\
\quad(\mathrm{N}=19)\end{array}$ & $\begin{array}{l}\text { Placebo } \\
\qquad(\mathrm{N}=9)\end{array}$ & $\begin{array}{l}\text { Clevudine } \\
(\mathrm{N}=19)\end{array}$ & $\begin{array}{l}\text { Placebo } \\
(\mathrm{N}=9)\end{array}$ & $\begin{array}{l}\text { Clevudine } \\
\quad(\mathrm{N}=19)\end{array}$ & $\begin{array}{l}\text { Placebo } \\
(\mathrm{N}=9)\end{array}$ \\
\hline \multirow[t]{5}{*}{ Day22 } & $\mathrm{N}$ & 14 & 9 & 14 & 9 & 14 & 9 \\
\hline & Mean \pm Std & $38.66 \pm 2.77$ & $39.64 \pm 1.08$ & $38.61 \pm 2.89$ & $38.89 \pm 1.85$ & $38.45 \pm 2.75$ & $37.54 \pm 2.85$ \\
\hline & Median & 40.00 & 40.00 & 40.00 & 40.00 & 40.00 & 37.46 \\
\hline & Min Max & $31.63 \sim 40.00$ & $36.76 \sim 40.00$ & $31.69 \sim 40.00$ & $35.69 \sim 40.00$ & $32.35 \sim 40.00$ & $31.76 \sim 40.00$ \\
\hline & P-value & \multicolumn{2}{|c|}{$0.4822 ¥$} & \multicolumn{2}{|c|}{$0.7172 ¥$} & \multicolumn{2}{|c|}{$0.3108 ¥$} \\
\hline \multirow[t]{5}{*}{ Day29 } & $\mathrm{N}$ & 15 & 9 & 15 & 9 & 15 & 9 \\
\hline & Mean \pm Std & $38.50 \pm 3.14$ & $39.35 \pm 1.95$ & $38.88 \pm 2.96$ & $38.92 \pm 2.41$ & $38.57 \pm 3.20$ & $38.72 \pm 2.45$ \\
\hline & Median & 40.00 & 40.00 & 40.00 & 40.00 & 40.00 & 40.00 \\
\hline & Min Max & $31.43 \sim 40.00$ & $34.16 \sim 40.00$ & $31.50 \sim 40.00$ & $32.91 \sim 40.00$ & $30.77 \sim 40.00$ & $33.42 \sim 40.00$ \\
\hline & P-value & \multicolumn{2}{|c|}{$0.5268 ¥$} & \multicolumn{2}{|c|}{$0.7508 ¥$} & \multicolumn{2}{|c|}{$0.6426 ¥$} \\
\hline Day4 - Baseline & $\mathrm{N}$ & 19 & 9 & 19 & 9 & 19 & 9 \\
\hline \multirow[t]{5}{*}{ (Change) } & Mean \pm Std & $5.22 \pm 5.12$ & $6.19 \pm 4.91$ & $5.22 \pm 4.63$ & $4.38 \pm 4.43$ & $4.68 \pm 4.71$ & $4.05 \pm 4.04$ \\
\hline & Median & 5.49 & 6.90 & 5.81 & 5.55 & 4.96 & 3.91 \\
\hline & Min Max & $-4.74 \sim 16.48$ & $-1.58 \sim 13.11$ & $-4.92 \sim 14.66$ & $-2.90 \sim 12.89$ & $-5.52 \sim 13.79$ & $-2.18 \sim 11.46$ \\
\hline & P-value (within) & $0.0003 \#$ & $0.0054 \#$ & $0.0001 \#$ & $0.0180 \#$ & $0.0004 \#$ & $0.0169 \#$ \\
\hline & P-value (between) & \multicolumn{2}{|c|}{$0.6414^{*}$} & \multicolumn{2}{|c|}{$0.6552^{*}$} & \multicolumn{2}{|c|}{$0.7318^{*}$} \\
\hline Day8 - Baseline & $\mathrm{N}$ & 17 & 9 & 17 & 9 & 17 & 9 \\
\hline \multirow[t]{5}{*}{ (Change) } & Mean \pm Std & $12.58 \pm 6.13$ & $11.48 \pm 4.10$ & $11.34 \pm 5.44$ & $8.51 \pm 3.95$ & $10.44 \pm 4.71$ & $7.81 \pm 3.39$ \\
\hline & Median & 12.93 & 12.82 & 10.84 & 8.37 & 10.70 & 7.51 \\
\hline & Min Max & $-1.45 \sim 24.34$ & $5.08 \sim 16.86$ & $-1.63 \sim 19.76$ & $4.00 \sim 15.74$ & $-0.59 \sim 18.04$ & $3.97 \sim 12.09$ \\
\hline & P-value (within) & $<.0001 \#$ & $<.0001 \#$ & $<.0001 \#$ & $0.0002 \#$ & $<.0001 \#$ & $0.0001 \#$ \\
\hline & P-value (between) & \multicolumn{2}{|c|}{$0.6339^{*}$} & \multicolumn{2}{|c|}{$0.1824^{*}$} & \multicolumn{2}{|c|}{$0.1530^{*}$} \\
\hline
\end{tabular}




\begin{tabular}{|c|c|c|c|c|c|c|c|}
\hline & & \multicolumn{2}{|c|}{ E gene } & \multicolumn{2}{|c|}{ RdRP gene } & \multicolumn{2}{|c|}{$\mathrm{N}$ gene } \\
\hline & & $\begin{array}{c}\text { Clevudine } \\
\quad(\mathrm{N}=19)\end{array}$ & $\begin{array}{l}\text { Placebo } \\
\qquad(\mathrm{N}=9)\end{array}$ & $\begin{array}{l}\text { Clevudine } \\
\qquad(\mathrm{N}=19)\end{array}$ & $\begin{array}{l}\text { Placebo } \\
\qquad(\mathrm{N}=9)\end{array}$ & $\begin{array}{l}\text { Clevudine } \\
\qquad(\mathrm{N}=19)\end{array}$ & $\begin{array}{l}\text { Placebo } \\
(\mathrm{N}=9)\end{array}$ \\
\hline Day11 - Baseline & $\mathrm{N}$ & 13 & 9 & 13 & 9 & 13 & 9 \\
\hline \multirow[t]{5}{*}{ (Change) } & Mean \pm Std & $14.08 \pm 7.63$ & $10.76 \pm 8.83$ & $12.77 \pm 6.09$ & $8.76 \pm 7.51$ & $11.39 \pm 5.48$ & $7.54 \pm 7.71$ \\
\hline & Median & 13.51 & 9.21 & 11.63 & 9.08 & 10.48 & 6.04 \\
\hline & Min Max & $5.18 \sim 27.74$ & $-2.69 \sim 28.13$ & $4.91 \sim 23.32$ & $-2.56 \sim 19.06$ & $3.98 \sim 20.57$ & $-3.33 \sim 22.01$ \\
\hline & P-value (within) & $<.0001 \#$ & $0.0064 \#$ & $<.0001 \#$ & $0.0081 \#$ & $<.0001 \#$ & 0.0189\# \\
\hline & P-value (between) & \multicolumn{2}{|c|}{$0.3571^{*}$} & \multicolumn{2}{|c|}{$0.1823^{*}$} & \multicolumn{2}{|c|}{$0.1849^{*}$} \\
\hline Day15 - Baseline & $\mathrm{N}$ & 15 & 9 & 15 & 9 & 15 & 9 \\
\hline \multirow[t]{5}{*}{ (Change) } & Mean \pm Std & $18.93 \pm 7.96$ & $11.48 \pm 7.08$ & $17.45 \pm 7.07$ & $10.56 \pm 6.24$ & $16.33 \pm 6.86$ & $9.32 \pm 6.41$ \\
\hline & Median & 21.18 & 11.11 & 19.40 & 10.13 & 18.83 & 7.53 \\
\hline & Min Max & $-0.53 \sim 28.16$ & $-1.59 \sim 20.69$ & $-0.56 \sim 25.60$ & $-1.03 \sim 18.38$ & $-0.74 \sim 24.63$ & $-1.95 \sim 20.15$ \\
\hline & P-value (within) & $<.0001 \#$ & $0.0012 \#$ & $<.0001 \#$ & $0.0010 \#$ & $<.0001 \#$ & $0.0024 \#$ \\
\hline & P-value (between) & \multicolumn{2}{|c|}{$0.0306^{*}$} & \multicolumn{2}{|c|}{$0.0249^{*}$} & \multicolumn{2}{|c|}{$0.0212^{*}$} \\
\hline Day22 - Baseline & $\mathrm{N}$ & 14 & 9 & 14 & 9 & 14 & 9 \\
\hline \multirow[t]{5}{*}{ (Change) } & Mean \pm Std & $20.58 \pm 6.21$ & $15.19 \pm 6.16$ & $19.04 \pm 5.64$ & $13.75 \pm 5.95$ & $17.70 \pm 5.62$ & $12.17 \pm 6.10$ \\
\hline & Median & 21.28 & 16.86 & 19.45 & 15.17 & 17.97 & 12.77 \\
\hline & Min Max & $6.61 \sim 28.16$ & $5.08 \sim 24.89$ & $5.31 \sim 25.60$ & $3.79 \sim 22.13$ & $4.81 \sim 24.63$ & $0.30 \sim 23.12$ \\
\hline & P-value (within) & $<.0001 \#$ & $<.0001 \#$ & $<.0001 \#$ & $0.0001 \#$ & $<.0001 \#$ & $0.0003 \#$ \\
\hline & P-value (between) & \multicolumn{2}{|c|}{$0.0543^{*}$} & \multicolumn{2}{|c|}{$0.0435^{\star}$} & \multicolumn{2}{|c|}{$0.0369^{*}$} \\
\hline Day29 - Baseline & $\mathrm{N}$ & 15 & 9 & 15 & 9 & 15 & 9 \\
\hline \multirow[t]{5}{*}{ (Change) } & Mean \pm Std & $20.22 \pm 5.67$ & $14.90 \pm 5.69$ & $19.25 \pm 4.71$ & $13.79 \pm 4.62$ & $17.81 \pm 4.72$ & $13.35 \pm 4.33$ \\
\hline & Median & 19.27 & 16.86 & 19.24 & 15.17 & 16.73 & 12.77 \\
\hline & Min Max & $11.30 \sim 28.16$ & $5.08 \sim 22.29$ & $11.21 \sim 25.60$ & $5.75 \sim 19.26$ & $10.51 \sim 24.63$ & 7.17 21.51 \\
\hline & P-value (within) & $<.0001 \#$ & $<.0001 \#$ & $<.0001 \#$ & $<.0001 \#$ & $<.0001 \#$ & $<.0001 \#$ \\
\hline & P-value (between) & \multicolumn{2}{|c|}{$0.0367^{*}$} & \multicolumn{2}{|c|}{$0.0111^{*}$} & \multicolumn{2}{|c|}{$0.0308^{*}$} \\
\hline
\end{tabular}

Note) *: Two sample t-test, $¥:$ Wilcoxon's rank sum test, \#: Paired t-test 
Table 5. Change in Ct value from baseline (patients with hypertension and randomized within 7 days after symptom onset, ITT set)

\begin{tabular}{|c|c|c|c|c|c|c|c|}
\hline & & \multicolumn{2}{|c|}{ E gene } & \multicolumn{2}{|c|}{ RdRP gene } & \multicolumn{2}{|c|}{ N gene } \\
\hline & & $\begin{array}{l}\text { Clevudine } \\
\quad(\mathrm{N}=16)\end{array}$ & $\begin{array}{l}\text { Placebo } \\
\qquad(\mathrm{N}=8)\end{array}$ & $\begin{array}{l}\text { Clevudine } \\
\qquad(\mathrm{N}=16)\end{array}$ & $\begin{array}{l}\text { Placebo } \\
\qquad(\mathrm{N}=8)\end{array}$ & $\begin{array}{l}\text { Clevudine } \\
\qquad(\mathrm{N}=16)\end{array}$ & $\begin{array}{l}\text { Placebo } \\
\qquad(\mathrm{N}=8)\end{array}$ \\
\hline \multirow[t]{5}{*}{ Baseline } & $\mathrm{N}$ & 16 & 8 & 16 & 8 & 16 & 8 \\
\hline & Mean \pm Std & $18.31 \pm 4.30$ & $24.33 \pm 7.32$ & $19.59 \pm 3.59$ & $24.93 \pm 6.57$ & $20.63 \pm 3.47$ & $25.14 \pm 6.50$ \\
\hline & Median & 18.59 & 23.075 & 19.815 & 23.685 & 20.78 & 25.34 \\
\hline & Min Max & $11.84 \sim 25.35$ & $11.87 \sim 34.92$ & $14.40 \sim 26.29$ & $13.65 \sim 34.25$ & 15.37 26.79 & $11.91 \sim 32.83$ \\
\hline & P-value & \multicolumn{2}{|c|}{$0.0182^{*}$} & \multicolumn{2}{|c|}{$0.0598^{*}$} & \multicolumn{2}{|c|}{$0.0994^{*}$} \\
\hline \multirow[t]{5}{*}{ Day4 } & $\mathrm{N}$ & 16 & 8 & 16 & 8 & 16 & 8 \\
\hline & Mean \pm Std & $23.44 \pm 4.54$ & $30.32 \pm 8.35$ & $24.82 \pm 4.18$ & $29.11 \pm 6.60$ & $25.36 \pm 3.81$ & $29.20 \pm 5.70$ \\
\hline & Median & 23.585 & 31.17 & 24.275 & 30.915 & 25.08 & 30.28 \\
\hline & Min Max & $15.38 \sim 29.34$ & $20.72 \sim 40.00$ & $17.47 \sim 30.76$ & $20.26 \sim 36.45$ & $18.70 \sim 31.60$ & $20.36 \sim 35.13$ \\
\hline & P-value & \multicolumn{2}{|c|}{$0.0573^{*}$} & \multicolumn{2}{|c|}{$0.0640^{*}$} & \multicolumn{2}{|c|}{$0.0613^{*}$} \\
\hline \multirow[t]{5}{*}{ Day8 } & $\mathrm{N}$ & 14 & 8 & 14 & 8 & 14 & 8 \\
\hline & Mean \pm Std & $29.69 \pm 6.26$ & $35.42 \pm 6.21$ & $29.88 \pm 5.45$ & $33.46 \pm 5.98$ & $30.27 \pm 4.97$ & $32.99 \pm 4.83$ \\
\hline & Median & 29.37 & 38.885 & 29.735 & 34.76 & 29.58 & 34.975 \\
\hline & Min Max & $19.28 \sim 40.00$ & $24.69 \sim 40.00$ & $20.28 \sim 40.00$ & $23.31 \sim 40.00$ & $22.68 \sim 40.00$ & $24.00 \sim 37.42$ \\
\hline & $\mathrm{P}$-value & \multicolumn{2}{|c|}{$0.0626 ¥$} & \multicolumn{2}{|c|}{$0.1674^{*}$} & \multicolumn{2}{|c|}{$0.2264^{*}$} \\
\hline \multirow[t]{5}{*}{ Day11 } & $\mathrm{N}$ & 13 & 8 & 13 & 8 & 13 & 8 \\
\hline & Mean \pm Std & $32.40 \pm 6.29$ & $34.62 \pm 4.69$ & $32.38 \pm 5.08$ & $33.65 \pm 4.53$ & $32.30 \pm 4.18$ & $32.87 \pm 4.33$ \\
\hline & Median & 31.11 & 33.24 & 33.34 & 32.295 & 32.34 & 32.435 \\
\hline & Min Max & $24.17 \sim 40.00$ & $29.30 \sim 40.00$ & $25.67 \sim 40.00$ & $28.49 \sim 40.00$ & $26.40 \sim 40.00$ & $28.13 \sim 40.00$ \\
\hline & P-value & \multicolumn{2}{|c|}{$0.3193 ¥$} & \multicolumn{2}{|c|}{$0.5713^{*}$} & \multicolumn{2}{|c|}{$0.7685^{*}$} \\
\hline \multirow[t]{5}{*}{ Day15 } & $\mathrm{N}$ & 13 & 8 & 13 & 8 & 13 & 8 \\
\hline & Mean \pm Std & $37.97 \pm 3.28$ & $35.42 \pm 4.04$ & $37.71 \pm 2.75$ & $35.16 \pm 4.24$ & $37.65 \pm 2.66$ & $34.57 \pm 4.69$ \\
\hline & Median & 40.00 & 34.225 & 38.80 & 33.725 & 37.36 & 33.015 \\
\hline & Min Max & $31.29 \sim 40.00$ & $31.37 \sim 40.00$ & $32.42 \sim 40.00$ & $30.87 \sim 40.00$ & $32.68 \sim 40.00$ & $29.51 \sim 40.00$ \\
\hline & P-value & & $0.1486 ¥$ & \multicolumn{2}{|c|}{$0.1629 ¥$} & \multicolumn{2}{|c|}{$0.1414 ¥$} \\
\hline
\end{tabular}




\begin{tabular}{|c|c|c|c|c|c|c|c|}
\hline & & \multicolumn{2}{|c|}{ E gene } & \multicolumn{2}{|c|}{ RdRP gene } & \multicolumn{2}{|c|}{ N gene } \\
\hline & & $\begin{array}{l}\text { Clevudine } \\
\qquad(\mathrm{N}=16)\end{array}$ & $\begin{array}{l}\text { Placebo } \\
\qquad(\mathrm{N}=8)\end{array}$ & $\begin{array}{l}\text { Clevudine } \\
\qquad(\mathrm{N}=16)\end{array}$ & $\begin{array}{l}\text { Placebo } \\
\qquad(\mathrm{N}=8)\end{array}$ & $\begin{array}{l}\text { Clevudine } \\
\qquad(\mathrm{N}=16)\end{array}$ & $\begin{array}{l}\text { Placebo } \\
\qquad(\mathrm{N}=8)\end{array}$ \\
\hline \multirow[t]{5}{*}{ Day22 } & $\mathrm{N}$ & 12 & 8 & 12 & 8 & 12 & 8 \\
\hline & Mean \pm Std & $39.13 \pm 2.04$ & $39.59 \pm 1.15$ & $39.07 \pm 2.26$ & $38.75 \pm 1.93$ & $38.83 \pm 2.28$ & $37.23 \pm 2.89$ \\
\hline & Median & 40.00 & 40.00 & 40.00 & 40.00 & 40.00 & 37.23 \\
\hline & Min Max & $34.69 \sim 40.00$ & $36.76 \sim 40.00$ & $32.99 \sim 40.00$ & $35.69 \sim 40.00$ & $33.53 \sim 40.00$ & $31.76 \sim 40.00$ \\
\hline & P-value & \multicolumn{2}{|c|}{$0.7564 ¥$} & \multicolumn{2}{|c|}{$0.3888 ¥$} & \multicolumn{2}{|c|}{$0.1388 ¥$} \\
\hline \multirow[t]{5}{*}{ Day29 } & $\mathrm{N}$ & 13 & 8 & 13 & 8 & 13 & 8 \\
\hline & Mean \pm Std & $38.27 \pm 3.32$ & $39.27 \pm 2.06$ & $38.70 \pm 3.16$ & $38.79 \pm 2.55$ & $38.34 \pm 3.40$ & $38.56 \pm 2.56$ \\
\hline & Median & 40.00 & 40.00 & 40.00 & 40.00 & 40.00 & 40.00 \\
\hline & Min Max & $31.43 \sim 40.00$ & $34.16 \sim 40.00$ & $31.50 \sim 40.00$ & $32.91 \sim 40.00$ & $30.77 \sim 40.00$ & $33.42 \sim 40.00$ \\
\hline & P-value & \multicolumn{2}{|c|}{$0.4924 ¥$} & \multicolumn{2}{|c|}{$0.7917 ¥$} & \multicolumn{2}{|c|}{$0.6829 ¥$} \\
\hline Day4 - Baseline & $\mathrm{N}$ & 16 & 8 & 16 & 8 & 16 & 8 \\
\hline \multirow[t]{5}{*}{ (Change) } & Mean \pm Std & $5.12 \pm 4.05$ & $5.98 \pm 5.21$ & $5.23 \pm 3.60$ & $4.17 \pm 4.69$ & $4.73 \pm 3.76$ & $4.07 \pm 4.32$ \\
\hline & Median & 5.84 & 5.99 & 5.84 & 4.08 & 5.265 & 3.31 \\
\hline & Min Max & $-2.17 \sim 11.48$ & $-1.58 \sim 13.11$ & $-1.72 \sim 11.66$ & $-2.90 \sim 12.89$ & $-1.88 \sim 10.88$ & $-2.18 \sim 11.46$ \\
\hline & P-value (within) & $0.0001 \#$ & $0.014 \#$ & $<.0001 \#$ & $0.0400 \#$ & $0.0001 \#$ & $0.0323 \#$ \\
\hline & P-value (between) & \multicolumn{2}{|c|}{$0.6597^{*}$} & \multicolumn{2}{|c|}{$0.5444^{*}$} & \multicolumn{2}{|c|}{$0.7003^{*}$} \\
\hline Day8 - Baseline & $\mathrm{N}$ & 14 & 8 & 14 & 8 & 14 & 8 \\
\hline \multirow[t]{5}{*}{ (Change) } & Mean \pm Std & $11.77 \pm 5.29$ & $11.10 \pm 4.20$ & $10.70 \pm 4.93$ & $8.53 \pm 4.23$ & $9.98 \pm 4.41$ & $7.85 \pm 3.63$ \\
\hline & Median & 12.145 & 12.435 & 10.79 & 8.88 & 9.74 & 7.72 \\
\hline & Min Max & $-1.45 \sim 19.46$ & $5.08 \sim 16.86$ & $-1.63 \sim 18.95$ & $4.00 \sim 15.74$ & $-0.59 \sim 17.68$ & $3.97 \sim 12.09$ \\
\hline & P-value (within) & $<.0001 \#$ & $0.0001 \#$ & $<.0001 \#$ & $0.0007 \#$ & $<.0001 \#$ & $0.0143 \$$ \\
\hline & P-value (between) & \multicolumn{2}{|c|}{$0.7614^{*}$} & \multicolumn{2}{|c|}{$0.3100^{*}$} & \multicolumn{2}{|c|}{$0.2613^{*}$} \\
\hline
\end{tabular}




\begin{tabular}{|c|c|c|c|c|c|c|c|}
\hline & & \multicolumn{2}{|c|}{ E gene } & \multicolumn{2}{|c|}{ RdRP gene } & \multicolumn{2}{|c|}{$\mathrm{N}$ gene } \\
\hline & & $\begin{array}{c}\text { Clevudine } \\
\quad(\mathrm{N}=16)\end{array}$ & $\begin{array}{l}\text { Placebo } \\
\qquad \mathrm{N}=8)\end{array}$ & $\begin{array}{l}\text { Clevudine } \\
(\mathrm{N}=16)\end{array}$ & $\begin{array}{l}\text { Placebo } \\
(\mathrm{N}=8)\end{array}$ & $\begin{array}{l}\text { Clevudine } \\
\quad(\mathrm{N}=16)\end{array}$ & $\begin{array}{l}\text { Placebo } \\
(\mathrm{N}=8)\end{array}$ \\
\hline Day11 - Baseline & $\mathrm{N}$ & 13 & 8 & 13 & 8 & 13 & 8 \\
\hline \multirow[t]{5}{*}{ (Change) } & Mean \pm Std & $14.45 \pm 7.30$ & $10.29 \pm 9.32$ & $13.06 \pm 5.77$ & $8.71 \pm 8.03$ & $11.85 \pm 5.32$ & $7.73 \pm 8.22$ \\
\hline & Median & 13.79 & 8.965 & 12.66 & 8.375 & 11.56 & 6.71 \\
\hline & Min Max & $5.18 \sim 27.74$ & $-2.69 \sim 28.13$ & $4.91 \sim 23.32$ & $-2.56 \sim 19.06$ & $3.98 \sim 20.57$ & $-3.33 \sim 22.01$ \\
\hline & P-value (within) & $<.0001 \#$ & $0.0168 \#$ & $<.0001 \#$ & $0.0181 \#$ & $<.0001 \#$ & $0.0325 \#$ \\
\hline & P-value (between) & \multicolumn{2}{|c|}{$0.2673^{*}$} & \multicolumn{2}{|c|}{$0.1647^{*}$} & \multicolumn{2}{|c|}{$0.1762^{*}$} \\
\hline Day15 - Baseline & $\mathrm{N}$ & 13 & 8 & 13 & 8 & 13 & 8 \\
\hline \multirow[t]{5}{*}{ (Change) } & Mean \pm Std & $20.02 \pm 6.22$ & $11.09 \pm 7.46$ & $18.39 \pm 5.26$ & $10.23 \pm 6.58$ & $17.20 \pm 5.20$ & $9.43 \pm 6.84$ \\
\hline & Median & 21.18 & 10.055 & 19.40 & 9.67 & 18.83 & 7.51 \\
\hline & Min Max & $11.22 \sim 28.16$ & $-1.59 \sim 20.69$ & $11.66 \sim 25.60$ & $-1.03 \sim 18.38$ & $9.82 \sim 24.63$ & $-1.95 \sim 20.15$ \\
\hline & P-value (within) & $<.0001 \#$ & $0.004 \#$ & $<.0001 \#$ & $0.0032 \#$ & $<.0001 \#$ & $0.0059 \#$ \\
\hline & P-value (between) & \multicolumn{2}{|c|}{$0.0080^{*}$} & \multicolumn{2}{|c|}{$0.0054^{*}$} & \multicolumn{2}{|c|}{$0.0082^{*}$} \\
\hline Day22 - Baseline & $\mathrm{N}$ & 12 & 8 & 12 & 8 & 12 & 8 \\
\hline \multirow[t]{5}{*}{ (Change) } & Mean \pm Std & $21.43 \pm 5.07$ & $15.27 \pm 6.58$ & $19.84 \pm 4.27$ & $13.81 \pm 6.36$ & $18.42 \pm 4.48$ & $12.09 \pm 6.51$ \\
\hline & Median & 21.275 & 16.925 & 19.45 & 16.00 & 17.965 & 12.955 \\
\hline & Min Max & $14.65 \sim 28.16$ & $5.08 \sim 24.89$ & $13.71 \sim 25.60$ & $3.79 \sim 22.13$ & $12.08 \sim 24.63$ & $0.30 \sim 23.12$ \\
\hline & P-value (within) & $<.0001 \#$ & $0.0003 \#$ & $<.0001 \#$ & $0.0005 \#$ & $<.0001 \#$ & $0.0012 \#$ \\
\hline & P-value (between) & \multicolumn{2}{|c|}{$0.0295^{*}$} & \multicolumn{2}{|c|}{$0.0202^{*}$} & \multicolumn{2}{|c|}{$0.0187^{*}$} \\
\hline Day29 - Baseline & $\mathrm{N}$ & 13 & 8 & 13 & 8 & 13 & 8 \\
\hline \multirow[t]{5}{*}{ (Change) } & Mean \pm Std & $20.31 \pm 5.81$ & $14.94 \pm 6.09$ & $19.38 \pm 4.68$ & $13.85 \pm 4.93$ & $17.90 \pm 4.71$ & $13.42 \pm 4.63$ \\
\hline & Median & 19.27 & 16.925 & 19.24 & 15.44 & 16.73 & 13.01 \\
\hline & Min Max & $11.30 \sim 28.16$ & $5.08 \sim 22.29$ & $11.21 \sim 25.60$ & $5.75 \sim 19.26$ & $10.51 \sim 24.63$ & 7.17 21.51 \\
\hline & P-value (within) & $<.0001 \#$ & $0.0002 \#$ & $<.0001 \#$ & $0.0001 \#$ & $<.0001 \#$ & $0.0001 \#$ \\
\hline & P-value (between) & \multicolumn{2}{|c|}{$0.0577^{*}$} & \multicolumn{2}{|c|}{$0.0185^{*}$} & \multicolumn{2}{|c|}{$0.0464^{*}$} \\
\hline
\end{tabular}

Note) *: Two sample t-test, $¥:$ Wilcoxon's rank sum test, \#: Paired t-test, \$: Wilcoxon’s signed rank test 
Table 6. Change in Ct value from baseline (patients randomized within 5 days after symptom onset, ITT set)

\begin{tabular}{|c|c|c|c|c|c|c|c|}
\hline & & \multicolumn{2}{|c|}{ E gene } & \multicolumn{2}{|c|}{ RdRP gene } & \multicolumn{2}{|c|}{$\mathrm{N}$ gene } \\
\hline & & $\begin{array}{c}\text { Clevudine } \\
(\mathrm{N}=21)\end{array}$ & $\begin{array}{c}\text { Placebo } \\
(\mathrm{N}=13)\end{array}$ & $\begin{array}{c}\text { Clevudine } \\
(\mathrm{N}=21)\end{array}$ & $\begin{array}{l}\text { Placebo } \\
(\mathrm{N}=13)\end{array}$ & $\begin{array}{c}\text { Clevudine } \\
(\mathrm{N}=21)\end{array}$ & $\begin{array}{c}\text { Placebo } \\
(\mathrm{N}=13)\end{array}$ \\
\hline \multirow[t]{5}{*}{ Baseline } & $\mathrm{N}$ & 21 & 13 & 21 & 13 & 21 & 13 \\
\hline & Mean \pm Std & $19.32 \pm 6.10$ & $24.46 \pm 7.65$ & $20.67 \pm 5.84$ & $24.91 \pm 6.58$ & $21.69 \pm 5.55$ & $25.44 \pm 6.19$ \\
\hline & Median & 19.63 & 23.01 & 20.76 & 23.76 & 21.52 & 25.74 \\
\hline & Min Max & $11.07 \sim 30.56$ & $11.87 \sim 40.00$ & $13.01 \sim 32.55$ & $13.65 \sim 37.05$ & $14.57 \sim 32.17$ & $11.91 \sim 35.84$ \\
\hline & P-value & \multicolumn{2}{|c|}{$0.0381^{*}$} & \multicolumn{2}{|c|}{$0.0588^{*}$} & \multicolumn{2}{|c|}{$0.0763^{*}$} \\
\hline \multirow[t]{4}{*}{ Day4 } & $\mathrm{N}$ & 21 & 13 & 21 & 13 & 21 & 13 \\
\hline & Mean \pm Std & $24.77 \pm 5.32$ & $29.56 \pm 7.50$ & $25.86 \pm 4.62$ & $28.78 \pm 5.78$ & $26.45 \pm 4.28$ & $29.17 \pm 5.65$ \\
\hline & Median & 24.50 & 27.20 & 24.59 & 27.61 & 25.46 & 28.29 \\
\hline & Min Max & $16.07 \sim 40.00$ & $20.72 \sim 40.00$ & $17.68 \sim 35.91$ & $20.26 \sim 36.45$ & $18.70 \sim 34.98$ & $20.36 \sim 38.83$ \\
\hline \multirow[t]{4}{*}{ Day8 } & $\mathrm{N}$ & 18 & 11 & 18 & 11 & 18 & 11 \\
\hline & Mean \pm Std & $28.31 \pm 5.39$ & $35.90 \pm 5.95$ & $29.35 \pm 5.04$ & $34.37 \pm 5.81$ & $29.65 \pm 4.37$ & $33.91 \pm 5.05$ \\
\hline & Median & 27.44 & 40.00 & 28.59 & 34.86 & 29.54 & 34.60 \\
\hline & Min Max & $19.28 \sim 40.00$ & $24.69 \sim 40.00$ & $20.28 \sim 37.21$ & $23.31 \sim 40.00$ & $22.68 \sim 35.66$ & $24.00 \sim 40.00$ \\
\hline \multirow[t]{4}{*}{ Day11 } & $\mathrm{N}$ & 17 & 11 & 17 & 11 & 17 & 11 \\
\hline & Mean \pm Std & $34.26 \pm 6.33$ & $35.30 \pm 4.63$ & $34.03 \pm 5.28$ & $33.91 \pm 4.35$ & $34.11 \pm 4.69$ & $33.44 \pm 3.98$ \\
\hline & Median & 37.91 & 33.72 & 34.92 & 32.11 & 33.78 & 33.35 \\
\hline & Min Max & $24.17 \sim 40.00$ & $29.30 \sim 40.00$ & $25.67 \sim 40.00$ & $28.49 \sim 40.00$ & $26.40 \sim 40.00$ & $28.13 \sim 40.00$ \\
\hline \multirow[t]{4}{*}{ Day15 } & $\mathrm{N}$ & 18 & 11 & 18 & 11 & 18 & 11 \\
\hline & Mean \pm Std & $35.47 \pm 6.28$ & $36.67 \pm 4.00$ & $35.73 \pm 5.57$ & $36.08 \pm 4.04$ & $35.64 \pm 5.20$ & $34.78 \pm 3.99$ \\
\hline & Median & 38.96 & 40.00 & 37.43 & 35.56 & 37.10 & 34.06 \\
\hline & Min Max & $16.29 \sim 40.00$ & $31.37 \sim 40.00$ & $18.13 \sim 40.00$ & $30.87 \sim 40.00$ & $19.31 \sim 40.00$ & $29.51 \sim 40.00$ \\
\hline
\end{tabular}




\begin{tabular}{|c|c|c|c|c|c|c|c|}
\hline & & \multicolumn{2}{|c|}{ E gene } & \multicolumn{2}{|c|}{ RdRP gene } & \multicolumn{2}{|c|}{$\mathrm{N}$ gene } \\
\hline & & $\begin{array}{l}\text { Clevudine } \\
(\mathrm{N}=21)\end{array}$ & $\begin{array}{l}\text { Placebo } \\
(\mathrm{N}=13)\end{array}$ & $\begin{array}{l}\text { Clevudine } \\
\qquad(\mathrm{N}=21)\end{array}$ & $\begin{array}{l}\text { Placebo } \\
(\mathrm{N}=13)\end{array}$ & $\begin{array}{l}\text { Clevudine } \\
(\mathrm{N}=21)\end{array}$ & $\begin{array}{l}\text { Placebo } \\
(\mathrm{N}=13)\end{array}$ \\
\hline \multirow[t]{4}{*}{ Day22 } & $\mathrm{N}$ & 17 & 11 & 17 & 11 & 17 & 11 \\
\hline & Mean \pm Std & $39.01 \pm 2.33$ & $39.71 \pm 0.98$ & $38.65 \pm 2.56$ & $39.09 \pm 1.72$ & $38.54 \pm 2.27$ & $38.30 \pm 2.76$ \\
\hline & Median & 40.00 & 40.00 & 40.00 & 40.00 & 40.00 & 40.00 \\
\hline & Min Max & $32.13 \sim 40.00$ & $36.76 \sim 40.00$ & $33.10 \sim 40.00$ & $35.69 \sim 40.00$ & $34.35 \sim 40.00$ & $31.76 \sim 40.00$ \\
\hline \multirow[t]{4}{*}{ Day29 } & $\mathrm{N}$ & 17 & 11 & 17 & 11 & 17 & 11 \\
\hline & Mean \pm Std & $39.63 \pm 1.53$ & $39.47 \pm 1.76$ & $40.00 \pm 0.00$ & $39.12 \pm 2.20$ & $39.55 \pm 1.28$ & $39.01 \pm 2.27$ \\
\hline & Median & 40.00 & 40.00 & 40.00 & 40.00 & 40.00 & 40.00 \\
\hline & Min Max & $33.70 \sim 40.00$ & $34.16 \sim 40.00$ & $40.00 \sim 40.00$ & $32.91 \sim 40.00$ & $35.88 \sim 40.00$ & $33.42 \sim 40.00$ \\
\hline Day4 - Baseline & $\mathrm{N}$ & 21 & 13 & 21 & 13 & 21 & 13 \\
\hline \multirow[t]{5}{*}{ (Change) } & Mean \pm Std & $5.44 \pm 3.89$ & $5.10 \pm 8.38$ & $5.18 \pm 3.56$ & $3.87 \pm 7.09$ & $4.76 \pm 3.62$ & $3.73 \pm 6.95$ \\
\hline & Median & 5.97 & 5.14 & 5.81 & 5.29 & 4.77 & 3.91 \\
\hline & Min Max & $-0.70 \sim 11.48$ & $-17.13 \sim 17.33$ & $-0.27 \sim 11.66$ & $-14.99 \sim 12.89$ & $-0.80 \sim 10.88$ & $-14.68 \sim 13.09$ \\
\hline & P-value (within) & $<.0001 \#$ & $0.0485 \#$ & $<.0001 \#$ & $0.0479 \$$ & $<.0001 \#$ & $0.0771 \#$ \\
\hline & P-value (between) & \multicolumn{2}{|c|}{$0.8923^{*}$} & \multicolumn{2}{|c|}{$0.8041 ¥$} & \multicolumn{2}{|c|}{$0.6257^{*}$} \\
\hline Day8 - Baseline & $\mathrm{N}$ & 18 & 11 & 18 & 11 & 18 & 11 \\
\hline \multirow[t]{5}{*}{ (Change) } & Mean \pm Std & $9.01 \pm 7.48$ & $12.53 \pm 4.31$ & $8.69 \pm 6.83$ & $10.30 \pm 4.72$ & $7.95 \pm 6.54$ & $9.20 \pm 3.95$ \\
\hline & Median & 9.60 & 13.11 & 8.55 & 10.03 & 8.12 & 9.97 \\
\hline & Min Max & $-1.78 \sim 20.41$ & $5.08 \sim 17.33$ & $-1.63 \sim 21.02$ & $4.00 \sim 16.24$ & $-1.65 \sim 19.12$ & $3.97 \sim 14.26$ \\
\hline & P-value (within) & $<.0001 \#$ & $<.0001 \#$ & $<.0001 \#$ & $<.0001 \#$ & $<.0001 \#$ & $<.0001 \#$ \\
\hline & P-value (between) & \multicolumn{2}{|c|}{$0.1679^{*}$} & \multicolumn{2}{|c|}{$0.4997^{*}$} & \multicolumn{2}{|c|}{$0.5720^{*}$} \\
\hline Day11 - Baseline & $\mathrm{N}$ & 17 & 11 & 17 & 11 & 17 & 11 \\
\hline \multirow[t]{5}{*}{ (Change) } & Mean \pm Std & $15.52 \pm 7.53$ & $11.93 \pm 8.36$ & $13.96 \pm 6.54$ & $9.84 \pm 7.11$ & $12.95 \pm 6.08$ & $8.74 \pm 7.24$ \\
\hline & Median & 13.79 & 11.66 & 12.66 & 10.21 & 11.56 & 8.64 \\
\hline & Min Max & $5.18 \sim 27.74$ & $-2.69 \sim 28.13$ & $4.91 \sim 25.97$ & $-2.56 \sim 19.06$ & $3.98 \sim 24.27$ & $-3.33 \sim 22.01$ \\
\hline & P-value (within) & $<.0001 \#$ & $0.0008 \#$ & $<.0001 \#$ & $0.0010 \#$ & $<.0001 \#$ & $0.0025 \#$ \\
\hline & P-value (between) & \multicolumn{2}{|c|}{$0.2487^{*}$} & \multicolumn{2}{|c|}{$0.1283^{*}$} & \multicolumn{2}{|c|}{$0.1082^{*}$} \\
\hline
\end{tabular}




\begin{tabular}{|c|c|c|c|c|c|c|c|}
\hline & & \multicolumn{2}{|c|}{ E gene } & \multicolumn{2}{|c|}{ RdRP gene } & \multicolumn{2}{|c|}{$\mathrm{N}$ gene } \\
\hline & & $\begin{array}{l}\text { Clevudine } \\
\qquad(\mathrm{N}=21)\end{array}$ & $\begin{array}{l}\text { Placebo } \\
(\mathrm{N}=13)\end{array}$ & $\begin{array}{l}\text { Clevudine } \\
\qquad(\mathrm{N}=21)\end{array}$ & $\begin{array}{l}\text { Placebo } \\
(\mathrm{N}=13)\end{array}$ & $\begin{array}{l}\text { Clevudine } \\
(\mathrm{N}=21)\end{array}$ & $\begin{array}{l}\text { Placebo } \\
(\mathrm{N}=13)\end{array}$ \\
\hline Day15 - Baseline & $\mathrm{N}$ & 18 & 11 & 18 & 11 & 18 & 11 \\
\hline \multirow[t]{5}{*}{ (Change) } & Mean \pm Std & $16.17 \pm 9.34$ & $13.30 \pm 7.53$ & $15.07 \pm 8.19$ & $12.01 \pm 6.70$ & $13.95 \pm 7.70$ & $10.07 \pm 5.91$ \\
\hline & Median & 16.97 & 16.86 & 16.34 & 12.89 & 14.43 & 10.48 \\
\hline & Min Max & $-5.32 \sim 28.93$ & $-1.59 \sim 24.06$ & $-4.49 \sim 25.60$ & $-1.03 \sim 22.84$ & $-4.49 \sim 24.63$ & $-1.95 \sim 20.15$ \\
\hline & P-value (within) & $<.0001 \#$ & $0.0002 \#$ & $<.0001 \#$ & $0.0001 \#$ & $<.0001 \#$ & $0.0002 \#$ \\
\hline & P-value (between) & \multicolumn{2}{|c|}{$0.3968^{*}$} & \multicolumn{2}{|c|}{$0.3059^{*}$} & \multicolumn{2}{|c|}{$0.1650^{*}$} \\
\hline Day22 - Baseline & $\mathrm{N}$ & 17 & 11 & 17 & 11 & 17 & 11 \\
\hline \multirow[t]{5}{*}{ (Change) } & Mean \pm Std & $19.88 \pm 7.40$ & $16.33 \pm 6.09$ & $18.21 \pm 6.53$ & $15.02 \pm 5.98$ & $17.05 \pm 6.32$ & $13.59 \pm 6.18$ \\
\hline & Median & 20.41 & 16.99 & 19.11 & 16.24 & 19.10 & 13.77 \\
\hline & Min Max & $6.21 \sim 28.93$ & $5.08 \sim 24.89$ & $6.38 \sim 25.97$ & 3.79 22.84 & $6.28 \sim 24.63$ & $0.30 \sim 23.12$ \\
\hline & P-value (within) & $<.0001 \#$ & $<.0001 \#$ & $<.0001 \#$ & $<.0001 \#$ & $<.0001 \#$ & $<.0001 \#$ \\
\hline & P-value (between) & \multicolumn{2}{|c|}{$0.1968^{*}$} & \multicolumn{2}{|c|}{$0.2037^{*}$} & \multicolumn{2}{|c|}{$0.1662^{*}$} \\
\hline Day29 - Baseline & $\mathrm{N}$ & 17 & 11 & 17 & 11 & 17 & 11 \\
\hline \multirow[t]{5}{*}{ (Change) } & Mean \pm Std & $20.51 \pm 6.91$ & $16.10 \pm 5.76$ & $19.56 \pm 6.35$ & $15.05 \pm 4.94$ & $18.05 \pm 6.34$ & $14.30 \pm 4.59$ \\
\hline & Median & 20.41 & 16.99 & 21.77 & 15.74 & 21.30 & 13.77 \\
\hline & Min Max & $9.44 \sim 28.93$ & $5.08 \sim 24.06$ & $7.45 \sim 26.99$ & $5.75 \sim 22.84$ & 7.83 25.43 & 7.17 21.67 \\
\hline & P-value (within) & $<.0001 \$$ & $<.0001 \#$ & $<.0001 \#$ & $<.0001 \#$ & $<.0001 \$$ & $<.0001 \#$ \\
\hline & P-value (between) & \multicolumn{2}{|c|}{$0.1206 ¥$} & \multicolumn{2}{|c|}{$0.0565^{\star}$} & \multicolumn{2}{|c|}{$0.1652 ¥$} \\
\hline
\end{tabular}


Table 7. Change in Ct value from baseline (patients randomized within 7 days after symptom onset, ITT set)

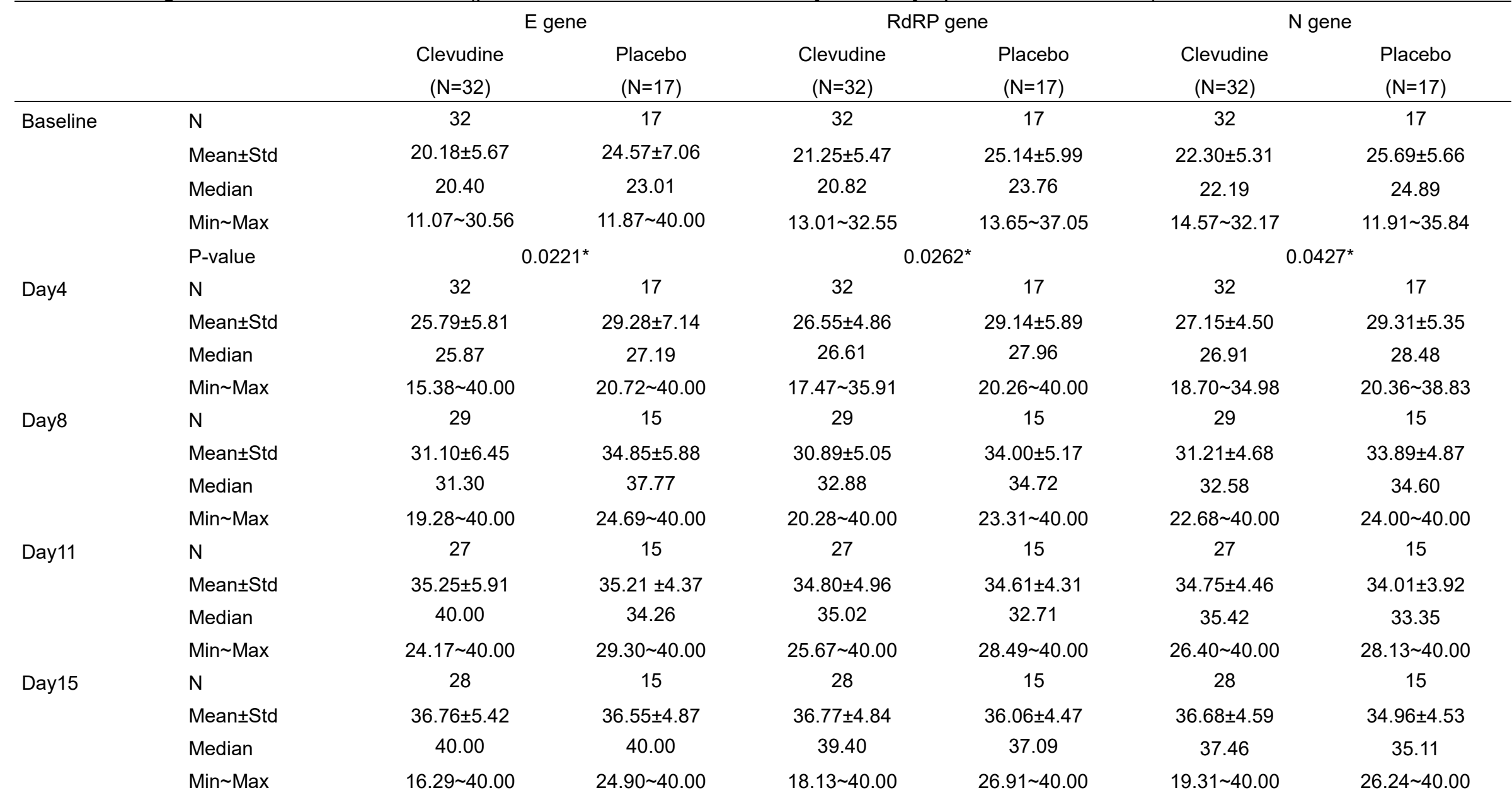




\begin{tabular}{|c|c|c|c|c|c|c|c|}
\hline & & \multicolumn{2}{|c|}{ E gene } & \multicolumn{2}{|c|}{ RdRP gene } & \multicolumn{2}{|c|}{$\mathrm{N}$ gene } \\
\hline & & $\begin{array}{l}\text { Clevudine } \\
\quad(\mathrm{N}=32)\end{array}$ & $\begin{array}{l}\text { Placebo } \\
(\mathrm{N}=17)\end{array}$ & $\begin{array}{l}\text { Clevudine } \\
\quad(\mathrm{N}=32)\end{array}$ & $\begin{array}{l}\text { Placebo } \\
(\mathrm{N}=17)\end{array}$ & $\begin{array}{l}\text { Clevudine } \\
\quad(\mathrm{N}=32)\end{array}$ & $\begin{array}{l}\text { Placebo } \\
(\mathrm{N}=17)\end{array}$ \\
\hline \multirow[t]{4}{*}{ Day22 } & $\mathrm{N}$ & 26 & 15 & 26 & 15 & 26 & 15 \\
\hline & Mean \pm Std & $38.81 \pm 2.60$ & $39.78 \pm 0.84$ & $38.57 \pm 2.71$ & $39.33 \pm 1.51$ & $38.52 \pm 2.50$ & $38.52 \pm 2.49$ \\
\hline & Median & 40.00 & 40.00 & 40.00 & 40.00 & 40.00 & 40.00 \\
\hline & Min Max & $31.40 \sim 40.00$ & $36.76 \sim 40.00$ & $32.82 \sim 40.00$ & $35.69 \sim 40.00$ & $32.75 \sim 40.00$ & $31.76 \sim 40.00$ \\
\hline \multirow[t]{4}{*}{ Day29 } & $\mathrm{N}$ & 27 & 14 & 27 & 14 & 27 & 14 \\
\hline & Mean \pm Std & $39.17 \pm 2.42$ & $39.58 \pm 1.56$ & $39.38 \pm 2.25$ & $39.31 \pm 1.97$ & $39.05 \pm 2.53$ & $39.18 \pm 2.02$ \\
\hline & Median & 40.00 & 40.00 & 40.00 & 40.00 & 40.00 & 40.00 \\
\hline & Min Max & $31.43 \sim 40.00$ & $34.16 \sim 40.00$ & $31.50 \sim 40.00$ & $32.91 \sim 40.00$ & $30.77 \sim 40.00$ & $33.42 \sim 40.00$ \\
\hline Day4 - Baseline & $\mathrm{N}$ & 32 & 17 & 32 & 17 & 32 & 17 \\
\hline \multirow[t]{5}{*}{ (Change) } & Mean \pm Std & $5.61 \pm 3.93$ & $4.71 \pm 7.34$ & $5.30 \pm 3.45$ & $3.99 \pm 6.29$ & $4.85 \pm 3.51$ & $3.62 \pm 6.07$ \\
\hline & Median & 6.35 & 4.73 & 5.84 & 5.01 & 4.66 & 4.06 \\
\hline & Min Max & $-2.17 \sim 12.16$ & $-17.13 \sim 17.33$ & $-1.72 \sim 11.66$ & $-14.99 \sim 12.89$ & $-1.88 \sim 10.92$ & $-14.68 \sim 13.09$ \\
\hline & P-value (within) & $<.0001 \#$ & $0.0038 \$$ & $<.0001 \#$ & $0.0079 \$$ & $<.0001 \#$ & $0.0056 \$$ \\
\hline & P-value (between) & \multicolumn{2}{|c|}{$0.7368 ¥$} & \multicolumn{2}{|c|}{$0.4948 ¥$} & \multicolumn{2}{|c|}{$0.4817 ¥$} \\
\hline Day8 - Baseline & $\mathrm{N}$ & 29 & 15 & 29 & 15 & 29 & 15 \\
\hline \multirow[t]{5}{*}{ (Change) } & Mean \pm Std & $10.85 \pm 6.46$ & $11.07 \pm 4.76$ & $9.59 \pm 5.86$ & $9.44 \pm 4.64$ & $8.84 \pm 5.62$ & $8.70 \pm 3.74$ \\
\hline & Median & 12.16 & 12.54 & 9.41 & 9.66 & 8.61 & 9.48 \\
\hline & Min Max & $-1.78 \sim 20.41$ & $3.08 \sim 17.33$ & $-1.63 \sim 21.02$ & $3.27 \sim 16.24$ & $-1.65 \sim 19.12$ & $3.86 \sim 14.26$ \\
\hline & P-value (within) & $<.0001 \#$ & $<.0001 \#$ & $<.0001 \#$ & $<.0001 \#$ & $<.0001 \#$ & $<.0001 \#$ \\
\hline & P-value (between) & \multicolumn{2}{|c|}{$0.9090^{*}$} & \multicolumn{2}{|c|}{$0.9326^{*}$} & \multicolumn{2}{|c|}{$0.9310^{*}$} \\
\hline
\end{tabular}




\begin{tabular}{|c|c|c|c|c|c|c|c|}
\hline & & \multicolumn{2}{|c|}{ E gene } & \multicolumn{2}{|c|}{ RdRP gene } & \multicolumn{2}{|c|}{$\mathrm{N}$ gene } \\
\hline & & $\begin{array}{l}\text { Clevudine } \\
\qquad(\mathrm{N}=32)\end{array}$ & $\begin{array}{l}\text { Placebo } \\
(\mathrm{N}=17)\end{array}$ & $\begin{array}{l}\text { Clevudine } \\
\quad(\mathrm{N}=32)\end{array}$ & $\begin{array}{l}\text { Placebo } \\
(\mathrm{N}=17)\end{array}$ & $\begin{array}{l}\text { Clevudine } \\
\quad(\mathrm{N}=32)\end{array}$ & $\begin{array}{l}\text { Placebo } \\
(\mathrm{N}=17)\end{array}$ \\
\hline Day11 - Baseline & $\mathrm{N}$ & 27 & 15 & 27 & 15 & 27 & 15 \\
\hline \multirow[t]{5}{*}{ (Change) } & Mean \pm Std & $15.21 \pm 6.79$ & $11.43 \pm 7.81$ & $13.70 \pm 5.94$ & $10.05 \pm 6.94$ & $12.55 \pm 5.54$ & $8.82 \pm 6.85$ \\
\hline & Median & 13.99 & 11.66 & 12.05 & 10.21 & 11.22 & 8.64 \\
\hline & Min Max & $5.18 \sim 27.74$ & $-2.69 \sim 28.13$ & $4.91 \sim 25.97$ & $-2.56 \sim 19.06$ & $3.98 \sim 24.27$ & $-3.33 \sim 22.01$ \\
\hline & P-value (within) & $<.0001 \#$ & $<.0001 \#$ & $<.0001 \#$ & $<.0001 \#$ & $<.0001 \#$ & $0.0002 \#$ \\
\hline & P-value (between) & \multicolumn{2}{|c|}{$0.1086^{*}$} & \multicolumn{2}{|c|}{$0.0803^{*}$} & \multicolumn{2}{|c|}{$0.0623^{*}$} \\
\hline Day15 - Baseline & $\mathrm{N}$ & 28 & 15 & 28 & 15 & 28 & 15 \\
\hline \multirow[t]{5}{*}{ (Change) } & Mean \pm Std & $16.41 \pm 7.85$ & $12.77 \pm 7.54$ & $15.33 \pm 7.00$ & $11.50 \pm 6.84$ & $14.17 \pm 6.59$ & $9.77 \pm 6.19$ \\
\hline & Median & 15.56 & 16.86 & 15.01 & 12.89 & 13.32 & 10.48 \\
\hline & Min Max & $-5.32 \sim 28.93$ & $-1.59 \sim 24.06$ & $-4.49 \sim 25.60$ & $-1.03 \sim 22.84$ & $-4.49 \sim 24.63$ & $-1.95 \sim 20.15$ \\
\hline & P-value (within) & $<.0001 \#$ & $<.0001 \#$ & $<.0001 \#$ & $<.0001 \#$ & $<.0001 \#$ & $<.0001 \#$ \\
\hline & P-value (between) & \multicolumn{2}{|c|}{$0.1498^{*}$} & \multicolumn{2}{|c|}{$0.0923^{*}$} & \multicolumn{2}{|c|}{$0.0393^{*}$} \\
\hline Day22 - Baseline & $\mathrm{N}$ & 26 & 15 & 26 & 15 & 26 & 15 \\
\hline \multirow[t]{5}{*}{ (Change) } & Mean \pm Std & $18.57 \pm 6.88$ & $16.00 \pm 5.79$ & $17.21 \pm 6.16$ & $14.77 \pm 5.42$ & $16.04 \pm 6.03$ & $13.34 \pm 5.52$ \\
\hline & Median & 18.83 & 16.99 & 17.12 & 16.24 & 15.69 & 13.77 \\
\hline & Min Max & $6.21 \sim 28.93$ & $5.08 \sim 24.89$ & $6.38 \sim 25.97$ & $3.79 \sim 22.84$ & $5.53 \sim 24.63$ & $0.30 \sim 23.12$ \\
\hline & P-value (within) & $<.0001 \#$ & $<.0001 \#$ & $<.0001 \#$ & $<.0001 \#$ & $<.0001 \#$ & $<.0001 \#$ \\
\hline & P-value (between) & \multicolumn{2}{|c|}{$0.2314^{*}$} & \multicolumn{2}{|c|}{$0.2114^{*}$} & \multicolumn{2}{|c|}{$0.1618^{*}$} \\
\hline Day29 - Baseline & $\mathrm{N}$ & 27 & 14 & 27 & 14 & 27 & 14 \\
\hline \multirow[t]{5}{*}{ (Change) } & Mean \pm Std & $18.89 \pm 6.29$ & $16.47 \pm 5.13$ & $18.05 \pm 5.95$ & $15.27 \pm 4.39$ & $16.64 \pm 5.86$ & $14.51 \pm 4.05$ \\
\hline & Median & 17.90 & 17.16 & 17.38 & 15.99 & 15.33 & 14.69 \\
\hline & Min Max & $9.44 \sim 28.93$ & $5.08 \sim 24.06$ & 7.45 26.99 & $5.75 \sim 22.84$ & $7.83 \sim 25.43$ & 7.17 21.67 \\
\hline & P-value (within) & $<.0001 \$$ & $<.0001 \$$ & $<.0001 \#$ & $<.0001 \#$ & $<.0001 \$$ & $<.0001 \#$ \\
\hline & P-value (between) & \multicolumn{2}{|c|}{$0.5362 ¥$} & \multicolumn{2}{|c|}{$0.1319^{*}$} & \multicolumn{2}{|c|}{$0.4747 ¥$} \\
\hline
\end{tabular}


medRxiv preprint doi: https://doi.org/10.1101/2021.12.09.21267566; this version posted December $14,2021$. The copyright holder for this preprint (which was not certified by peer review) is the author/funder, who has granted medRxiv a license to display the preprint in It is made available under a CC-BY-NC-ND 4.0 International license.

Table 8. Proportion of patients who showed improvement in lung involvement (ITT set)

\begin{tabular}{|c|c|c|c|c|}
\hline & & $\begin{array}{c}\text { Clevudine } \\
(\mathrm{N}=41)\end{array}$ & $\begin{array}{c}\text { Placebo } \\
(\mathrm{N}=20)\end{array}$ & $\begin{array}{c}\text { Total } \\
(\mathrm{N}=61)\end{array}$ \\
\hline \multirow[t]{4}{*}{ Day29(EOT) } & Improvement & $23(82.14 \%)$ & $15(100.00 \%)$ & $38(88.37 \%)$ \\
\hline & No change or Aggravation & $5(17.86 \%)$ & $0(0.00 \%)$ & $5(11.63 \%)$ \\
\hline & Total & $28(65.12 \%)$ & $15(34.88 \%)$ & $43(100.00 \%$ \\
\hline & P-value & $0.1449 \ddagger$ & & . \\
\hline
\end{tabular}

Note) ‡: Fisher's exact test 
medRxiv preprint doi: https://doi.org/10.1101/2021.12.09.21267566; this version posted December 14,2021 . The copyright holder for this preprint (which was not certified by peer review) is the author/funder, who has granted medRxiv a license to display the preprint in It is made available under a CC-BY-NC-ND 4.0 International license

Table 9. Proportion of patients with normal body temperature (ITT set)

\begin{tabular}{|c|c|c|c|c|}
\hline & & $\begin{array}{c}\text { Clevudine } \\
(\mathrm{N}=41)\end{array}$ & $\begin{array}{l}\text { Placebo } \\
(\mathrm{N}=20)\end{array}$ & $\begin{array}{c}\text { Total } \\
(\mathrm{N}=61)\end{array}$ \\
\hline \multirow[t]{4}{*}{ Day4 } & Normal & $26(72.22 \%)$ & $14(82.35 \%)$ & $40(75.47 \%)$ \\
\hline & Abnormal & $10(27.78 \%)$ & $3(17.65 \%)$ & $13(24.53 \%)$ \\
\hline & Total & $36(67.92 \%)$ & $17(32.08 \%)$ & $53(100.00 \%)$ \\
\hline & P-value & $0.5112 \ddagger$ & . & . \\
\hline \multirow[t]{4}{*}{ Day8 } & Normal & $21(63.64 \%)$ & 11(73.33\%) & $32(66.67 \%)$ \\
\hline & Abnormal & $12(36.36 \%)$ & $4(26.67 \%)$ & $16(33.33 \%)$ \\
\hline & Total & $33(68.75 \%)$ & $15(31.25 \%)$ & $48(100.00 \%)$ \\
\hline & P-value & $0.5089 \dagger$ & ${ }^{\circ}$ & . \\
\hline \multirow[t]{4}{*}{ Day11 } & Normal & $17(60.71 \%)$ & $12(80.00 \%)$ & $29(67.44 \%)$ \\
\hline & Abnormal & $11(39.29 \%)$ & $3(20.00 \%)$ & $14(32.56 \%)$ \\
\hline & Total & $28(65.12 \%)$ & $15(34.88 \%)$ & $43(100.00 \%)$ \\
\hline & P-value & $0.3084 \ddagger$ & . & . \\
\hline \multirow[t]{4}{*}{ Day15 } & Normal & $22(73.33 \%)$ & $11(73.33 \%)$ & $33(73.33 \%)$ \\
\hline & Abnormal & $8(26.67 \%)$ & $4(26.67 \%)$ & $12(26.67 \%)$ \\
\hline & Total & $30(66.67 \%)$ & 15(33.33\%) & $45(100.00 \%)$ \\
\hline & P-value & $>.9999 \ddagger$ & & . \\
\hline \multirow[t]{4}{*}{ Day22 } & Normal & $23(95.83 \%)$ & 13(92.86\%) & $36(94.74 \%)$ \\
\hline & Abnormal & $1(4.17 \%)$ & $1(7.14 \%)$ & $2(5.26 \%)$ \\
\hline & Total & $24(63.16 \%)$ & $14(36.84 \%)$ & $38(100.00 \%)$ \\
\hline & P-value & $>.9999 \ddagger$ & & . \\
\hline \multirow[t]{4}{*}{ Day29 } & Normal & $18(94.74 \%)$ & $10(100.00 \%)$ & $28(96.55 \%)$ \\
\hline & Abnormal & $1(5.26 \%)$ & $0(0.00 \%)$ & $1(3.45 \%)$ \\
\hline & Total & $19(65.52 \%)$ & $10(34.48 \%)$ & $29(100.00 \%)$ \\
\hline & $P$-value & $>.9999 \ddagger$ & & \\
\hline
\end{tabular}

Note) †: Pearson's chi-square test, ‡: Fisher's exact test 
medRxiv preprint doi: https://doi.org/10.1101/2021.12.09.21267566; this version posted December 14,2021 . The copyright holder for this preprint (which was not certified by peer review) is the author/funder, who has granted medRxiv a license to display the preprint in It is made available under a CC-BY-NC-ND 4.0 International license.

Table 10. Proportion of patients with normal oxygen saturation (ITT set)

\begin{tabular}{llccc}
\hline & & $\begin{array}{c}\text { Clevudine } \\
(\mathrm{N}=41)\end{array}$ & $\begin{array}{c}\text { Placebo } \\
(\mathrm{N}=20)\end{array}$ & $\begin{array}{c}\text { Total } \\
(\mathrm{N}=61)\end{array}$ \\
\hline Day4 & Normal & $35(100.00 \%)$ & $18(94.74 \%)$ & $53(98.15 \%)$ \\
& Abnormal & $0(0.00 \%)$ & $1(5.26 \%)$ & $1(1.85 \%)$ \\
& Total & $35(64.81 \%)$ & $19(35.19 \%)$ & $54(100.00 \%)$ \\
Day8 & P-value & $0.3519 \ddagger$ & $\cdot$ &. \\
& Normal & $29(87.88 \%)$ & $11(68.75 \%)$ & $40(81.63 \%)$ \\
& Abnormal & $4(12.12 \%)$ & $5(31.25 \%)$ & $9(18.37 \%)$ \\
Day11 & Total & $33(67.35 \%)$ & $16(32.65 \%)$ & $49(100.00 \%)$ \\
& P-value & $0.1302 \ddagger$ &. &. \\
& Normal & $18(60.00 \%)$ & $14(77.78 \%)$ & $32(66.67 \%)$ \\
& Abnormal & $12(40.00 \%)$ & $4(22.22 \%)$ & $16(33.33 \%)$ \\
& Total & $30(62.50 \%)$ & $18(37.50 \%)$ & $48(100.00 \%)$ \\
& P-value & $0.2059 \dagger$ &. &. \\
& Normal & $24(70.59 \%)$ & $14(77.78 \%)$ & $38(73.08 \%)$ \\
& Abnormal & $10(29.41 \%)$ & $4(22.22 \%)$ & $14(26.92 \%)$ \\
& Total & $34(65.38 \%)$ & $18(34.62 \%)$ & $52(100.00 \%)$ \\
& P-value & $0.7460 \ddagger$ &. &. \\
& Normal & $24(88.89 \%)$ & $17(100.00 \%)$ & $41(93.18 \%)$ \\
& Abnormal & $3(11.11 \%)$ & $0(0.00 \%)$ & $3(6.82 \%)$ \\
& Total & $27(61.36 \%)$ & $17(38.64 \%)$ & $44(100.00 \%)$ \\
& P-value & $0.2722 \ddagger$ &. &. \\
& Normal & $20(95.24 \%)$ & $12(100.00 \%)$ & $32(96.97 \%)$ \\
& Abnormal & $1(4.76 \%)$ & $0(0.00 \%)$ & $1(3.03 \%)$ \\
& Total & $21(63.64 \%)$ & $12(36.36 \%)$ & $33(100.00 \%)$ \\
& P-value & $>.9999 \ddagger$ &. &. \\
\hline
\end{tabular}

Note) †: Pearson's chi-square test, ‡: Fisher's exact test 
medRxiv preprint doi: https://doi.org/10.1101/2021.12.09.21267566; this version posted December 14,2021 . The copyright holder for this preprint (which was not certified by peer review) is the author/funder, who has granted medRxiv a license to display the preprint in It is made available under a CC-BY-NC-ND 4.0 International license

Table 11. Change in CRP from baseline (ITT set)

\begin{tabular}{|c|c|c|c|c|}
\hline & & $\begin{array}{c}\text { Clevudine } \\
(\mathrm{N}=41)\end{array}$ & $\begin{array}{c}\text { Placebo } \\
(\mathrm{N}=20)\end{array}$ & $\begin{array}{l}\text { Total } \\
(\mathrm{N}=61)\end{array}$ \\
\hline \multirow[t]{5}{*}{ Baseline } & $\mathrm{N}$ & 40 & 19 & 59 \\
\hline & Mean \pm Std & $3.20 \pm 3.60$ & $1.42 \pm 1.36$ & $2.63 \pm 3.16$ \\
\hline & Median & 1.76 & 0.92 & 1.33 \\
\hline & Min Max & $0.08 \sim 14.80$ & $0.30 \sim 5.60$ & $0.08 \sim 14.80$ \\
\hline & P-value & $0.1101 ¥$ & . & . \\
\hline \multirow[t]{5}{*}{ Day4 } & $\mathrm{N}$ & 41 & 20 & 61 \\
\hline & Mean \pm Std & $3.24 \pm 3.08$ & $1.91 \pm 2.26$ & $2.80 \pm 2.88$ \\
\hline & Median & 2.12 & 0.80 & 1.48 \\
\hline & Min Max & $0.05 \sim 13.30$ & $0.05 \sim 8.60$ & $0.05 \sim 13.30$ \\
\hline & P-value & $0.0876 ¥$ & . & . \\
\hline \multirow[t]{5}{*}{ Day8 } & $N$ & 38 & 18 & 56 \\
\hline & Mean $\pm S t d$ & $2.41 \pm 2.52$ & $1.53 \pm 2.84$ & $2.12 \pm 2.64$ \\
\hline & Median & 1.19 & 0.60 & 0.89 \\
\hline & Min Max & $0.05 \sim 8.80$ & $0.05 \sim 10.50$ & $0.05 \sim 10.50$ \\
\hline & P-value & $0.0503 ¥$ & . & . \\
\hline \multirow[t]{5}{*}{ Day15 } & $\mathrm{N}$ & 35 & 18 & 53 \\
\hline & Mean \pm Std & $0.46 \pm 0.50$ & $0.52 \pm 0.55$ & $0.48 \pm 0.51$ \\
\hline & Median & 0.30 & 0.40 & 0.30 \\
\hline & Min Max & $0.01 \sim 2.60$ & $0.05 \sim 2.40$ & $0.01 \sim 2.60$ \\
\hline & P-value & $0.6453 ¥$ & . & . \\
\hline \multirow[t]{5}{*}{ Day22 } & $N$ & 27 & 16 & 43 \\
\hline & Mean $\pm S t d$ & $0.34 \pm 0.36$ & $0.48 \pm 0.45$ & $0.39 \pm 0.40$ \\
\hline & Median & 0.30 & 0.40 & 0.30 \\
\hline & Min Max & $0.03 \sim 1.50$ & $0.03 \sim 1.80$ & $0.03 \sim 1.80$ \\
\hline & P-value & $0.3943 ¥$ & . & . \\
\hline \multirow[t]{5}{*}{ Day29 } & $N$ & 21 & 12 & 33 \\
\hline & Mean \pm Std & $0.82 \pm 2.40$ & $0.39 \pm 0.29$ & $0.66 \pm 1.92$ \\
\hline & Median & 0.30 & 0.33 & 0.30 \\
\hline & Min Max & $0.03 \sim 11.23$ & $0.05 \sim 0.90$ & $0.03 \sim 11.23$ \\
\hline & P-value & $0.6953 ¥$ & . & . \\
\hline Day4 - Baseline & $N$ & 40 & 19 & 59 \\
\hline \multirow[t]{5}{*}{ (Change) } & Mean \pm Std & $-0.02 \pm 2.54$ & $0.58 \pm 1.84$ & $0.17 \pm 2.34$ \\
\hline & Median & 0.29 & 0.13 & 0.20 \\
\hline & Min Max & $-7.39 \sim 6.32$ & $-1.60 \sim 6.10$ & $-7.39 \sim 6.32$ \\
\hline & P-value(within) & $0.4094 \$$ & $0.4471 \$$ & $0.2097 \$$ \\
\hline & P-value(between) & $0.9100 ¥$ & . & . \\
\hline
\end{tabular}


medRxiv preprint doi: https://doi.org/10.1101/2021.12.09.21267566; this version posted December 14,2021 . The copyright holder for this preprint (which was not certified by peer review) is the author/funder, who has granted medRxiv a license to display the preprint in It is made available under a CC-BY-NC-ND 4.0 International license.

\begin{tabular}{|c|c|c|c|c|}
\hline & & $\begin{array}{l}\text { Clevudine } \\
\qquad(\mathrm{N}=41)\end{array}$ & $\begin{array}{l}\text { Placebo } \\
(\mathrm{N}=20)\end{array}$ & $\begin{array}{c}\text { Total } \\
(\mathrm{N}=61)\end{array}$ \\
\hline Day8 - Baseline & $\mathrm{N}$ & 37 & 17 & 54 \\
\hline \multirow[t]{5}{*}{ (Change) } & Mean \pm Std & $-0.83 \pm 3.95$ & $0.10 \pm 2.31$ & $-0.54 \pm 3.52$ \\
\hline & Median & -0.10 & 0.00 & -0.09 \\
\hline & Min Max & $-9.72 \sim 7.24$ & $-2.82 \sim 8.00$ & $-9.72 \sim 8.00$ \\
\hline & P-value(within) & $0.2077 \#$ & $0.5417 \$$ & $0.2350 \$$ \\
\hline & P-value(between) & $0.6836 ¥$ & . & . \\
\hline Day15 - Baseline & $\mathrm{N}$ & 34 & 17 & 51 \\
\hline \multirow[t]{5}{*}{ (Change) } & Mean \pm Std & $-2.34 \pm 3.34$ & $-0.97 \pm 1.49$ & $-1.88 \pm 2.92$ \\
\hline & Median & -1.00 & -0.46 & -0.88 \\
\hline & Min Max & $-11.61 \sim 1.15$ & $-5.20 \sim 0.70$ & $-11.61 \sim 1.15$ \\
\hline & P-value(within) & $<.0001 \$$ & $0.0024 \$$ & $<.0001 \$$ \\
\hline & P-value(between) & $0.3224 ¥$ & . & . \\
\hline Day22 - Baseline & $\mathrm{N}$ & 26 & 16 & 42 \\
\hline \multirow[t]{5}{*}{ (Change) } & Mean \pm Std & $-2.47 \pm 2.98$ & $-1.07 \pm 1.60$ & $-1.93 \pm 2.61$ \\
\hline & Median & -1.73 & -0.90 & -1.27 \\
\hline & Min Max & $-10.00 \sim 0.90$ & $-5.10 \sim 1.50$ & $-10.00 \sim 1.50$ \\
\hline & P-value(within) & $<.0001 \$$ & $0.0176 \#$ & $<.0001 \$$ \\
\hline & P-value(between) & $0.1374 ¥$ & . & . \\
\hline Day29 - Baseline & $\mathrm{N}$ & 21 & 11 & 32 \\
\hline \multirow[t]{5}{*}{ (Change) } & Mean \pm Std & $-1.99 \pm 2.67$ & $-1.19 \pm 1.55$ & $-1.72 \pm 2.35$ \\
\hline & Median & -1.20 & -1.08 & -1.14 \\
\hline & Min Max & $-9.90 \sim 2.34$ & $-5.30 \sim 0.60$ & $-9.90 \sim 2.34$ \\
\hline & P-value(within) & $0.0001 \$$ & $0.0088 \$$ & $<.0001 \$$ \\
\hline & P-value(between) & $0.4804 ¥$ & . & . \\
\hline
\end{tabular}

Note) $¥:$ Wilcoxon's rank sum test, \#: Paired t-test, \$: Wilcoxon’s signed rank test 
medRxiv preprint doi: https://doi.org/10.1101/2021.12.09.21267566; this version posted December 14,2021 . The copyright holder for this preprint (which was not certified by peer review) is the author/funder, who has granted medRxiv a license to display the preprint in It is made available under a CC-BY-NC-ND 4.0 International license.

Figure 1. Clinical study oversight.

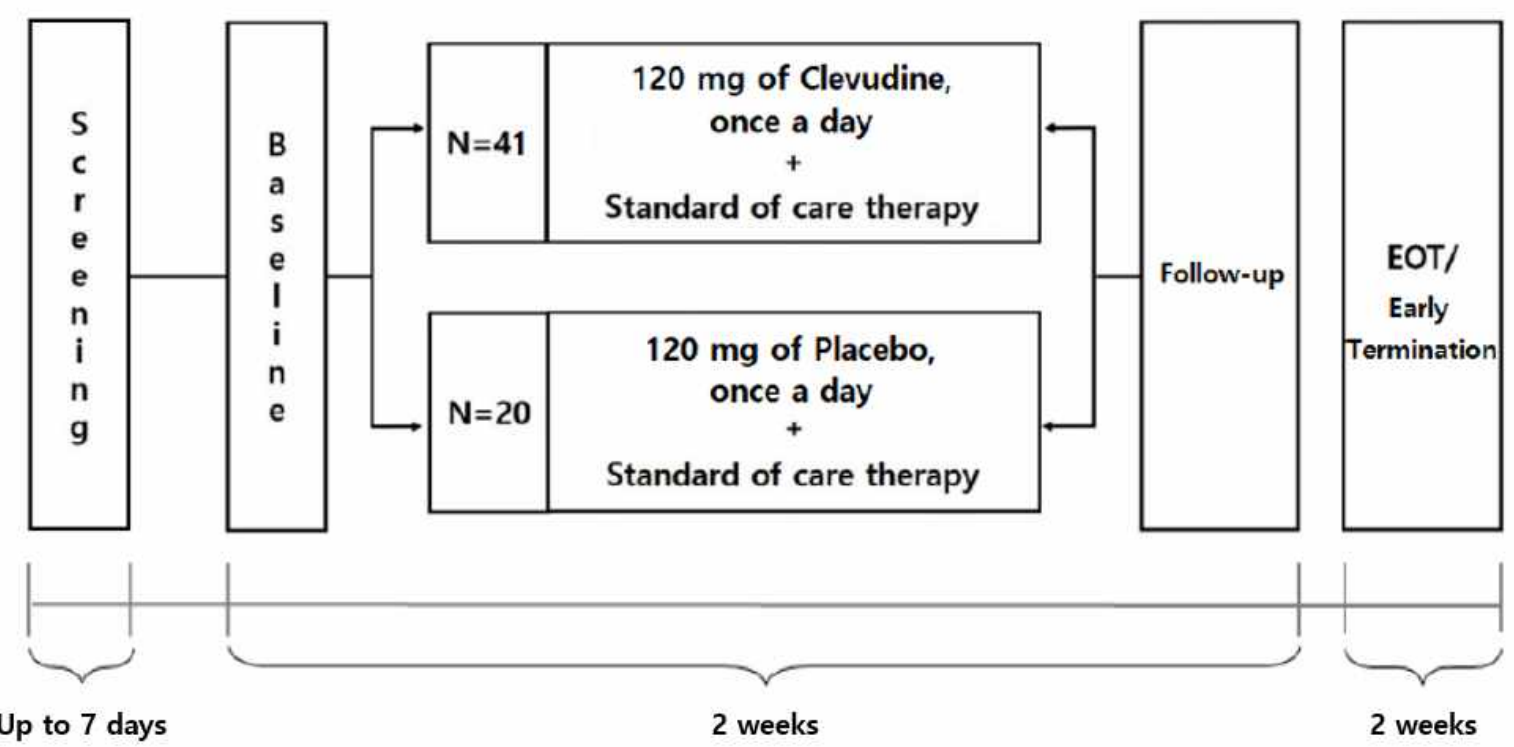

Figure 2. Change in Ct value from baseline (ITT set)

E

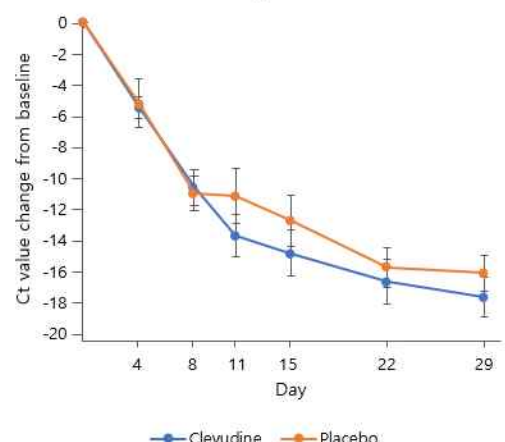

$\rightarrow$ Clevudine $\rightarrow-$ Placebo
RdRP

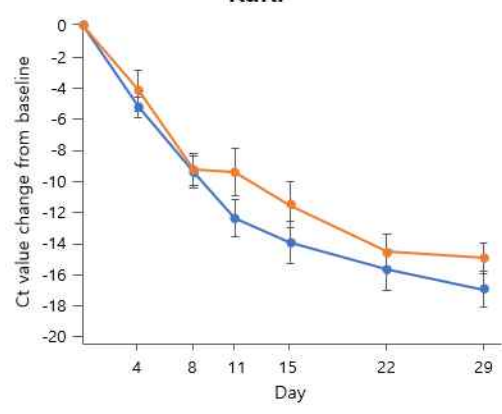

$\rightarrow$-Clevudine $\rightarrow$-Placebo

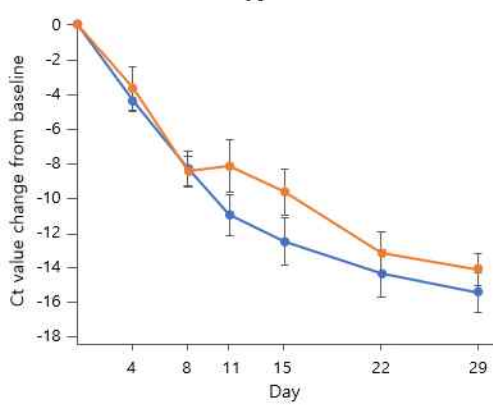

$\rightarrow$ Clevudine $\rightarrow$ Placebo

Note) ${ }^{*} \mathrm{P}<0.1,{ }^{* *} \mathrm{P}<0.05,{ }^{* * *} \mathrm{P}<0.01$ 
medRxiv preprint doi: https://doi.org/10.1101/2021.12.09.21267566; this version posted December 14,2021 . The copyright holder for this preprint (which was not certified by peer review) is the author/funder, who has granted medRxiv a license to display the preprint in It is made available under a CC-BY-NC-ND 4.0 International license.

Figure 3. Change in Ct value from baseline (patients with hypertension, ITT set)

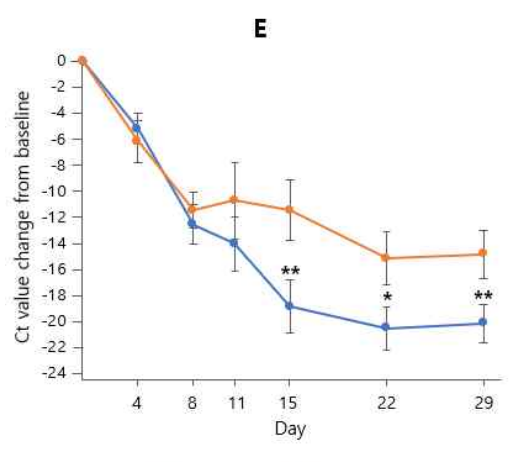

$\rightarrow$ Clevudine $\rightarrow$ - Placebo
RdRP

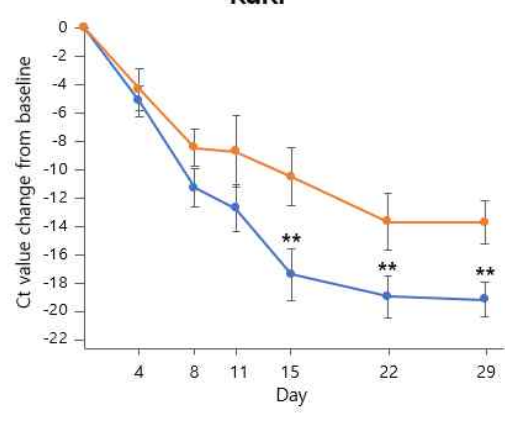

- Clevudine - - Placebo
N

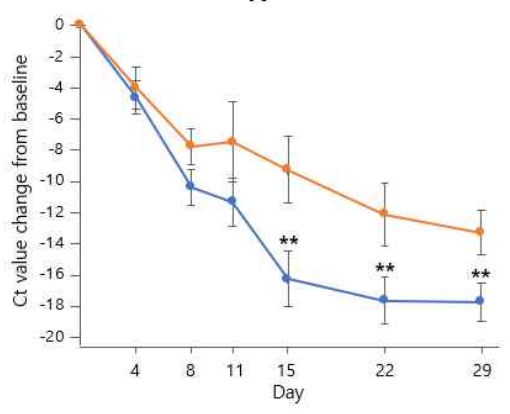

$\rightarrow-$ Clevudine $\rightarrow-$ Placebo

Note) ${ }^{*} \mathrm{P}<0.1,{ }^{* *} \mathrm{P}<0.05,{ }^{* *} \mathrm{P}<0.01$

Figure 4. Change in Ct value from baseline (patients with hypertension and randomized within 7 days after symptom onset, ITT set)

E

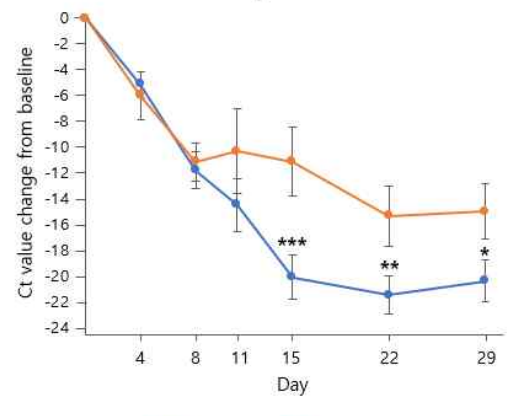

$\rightarrow$ Clevudine $\rightarrow$ Placebo
RdRP

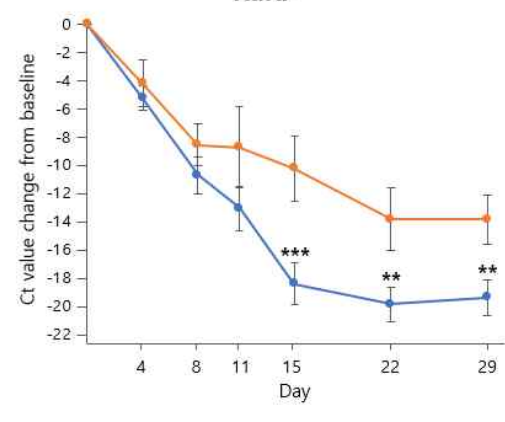

-Clevudine - Placebo
N

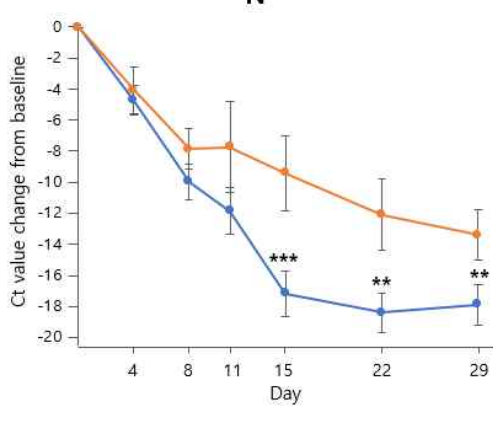

-Clevudine -Placebo

Note) ${ }^{*} \mathrm{P}<0.1,{ }^{* *} \mathrm{P}<0.05,{ }^{* * *} \mathrm{P}<0.01$ 
medRxiv preprint doi: https://doi.org/10.1101/2021.12.09.21267566; this version posted December 14,2021 . The copyright holder for this preprint (which was not certified by peer review) is the author/funder, who has granted medRxiv a license to display the preprint in It is made available under a CC-BY-NC-ND 4.0 International license.

Figure 5. Change in Ct value from baseline (patients randomized within 5 days after symptom onset, ITT set)

E

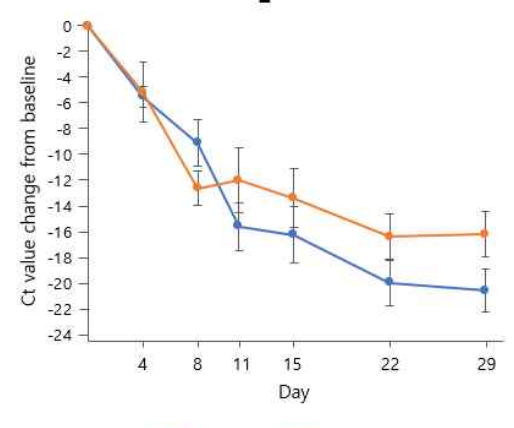

- Clevudine -Placebo
RdRP

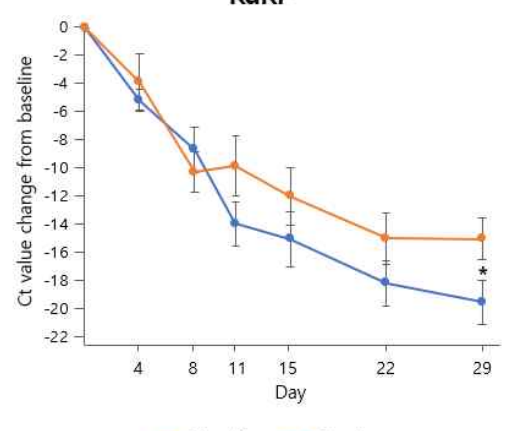

$\rightarrow$ Clevudine $\rightarrow$ - Placebo
$\mathrm{N}$

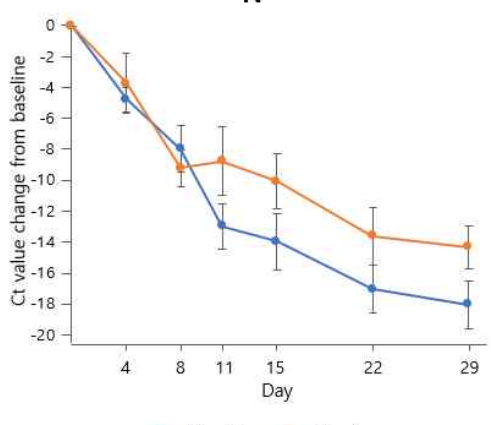

Note) ${ }^{*} \mathrm{P}<0.1,{ }^{* *} \mathrm{P}<0.05,{ }^{* * *} \mathrm{P}<0.01$

Figure 6. Change in Ct value from baseline (patients randomized within 7 days after symptom onset, ITT set)

E

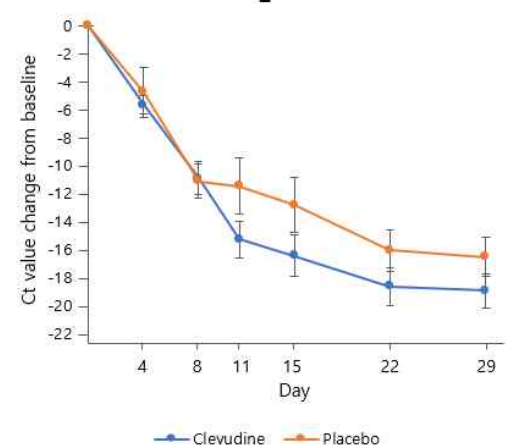

-Clevudine -Placebo
RdRP

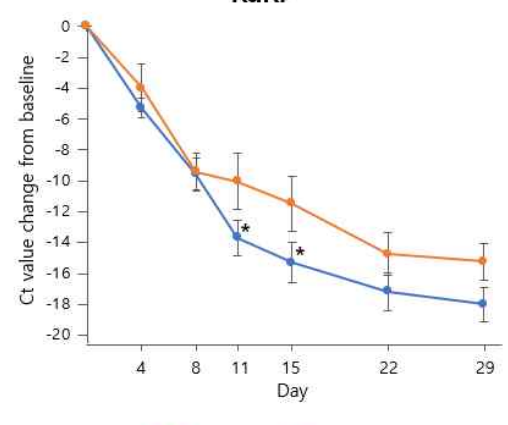

-Clevudine -Placebo
N

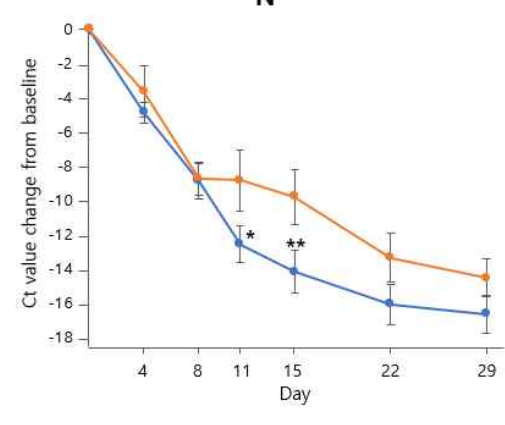

- Clevudine $\rightarrow$ Placebo

Note) ${ }^{*} \mathrm{P}<0.1,{ }^{* *} \mathrm{P}<0.05,{ }^{* * *} \mathrm{P}<0.01$ 